\title{
Impact of dietary fatty acids on metabolic activity and host intestinal microbiota composition in C57BL/6J mice
}

\author{
Elaine Patterson ${ }^{1,2,3}$, Robert M. O’ Doherty ${ }^{4 *}$, Eileen F. Murphy ${ }^{1,5}$, Rebecca Wall ${ }^{1,2}$, Orla O' Sullivan ${ }^{1,2}$, \\ Kanishka Nilaweera $^{2}$, Gerald F. Fitzgerald ${ }^{1,3}$, Paul D. Cotter ${ }^{1,2}$, R. Paul Ross ${ }^{1,2}$ and Catherine Stanton ${ }^{1,2 *}$ \\ ${ }^{1}$ Alimentary Pharmabiotic Centre, Biosciences Institute, Cork, Republic of Ireland \\ ${ }^{2}$ Teagasc Food Research Centre, Biosciences Department, Moorepark, Fermoy, Cork, Republic of Ireland \\ ${ }^{3}$ Department of Microbiology, University College Cork, Cork, Republic of Ireland \\ ${ }^{4}$ Division of Endocrinology and Metabolism, University of Pittsburgh School of Medicine, Pittsburgh, PA, USA \\ ${ }^{5}$ Alimentary Health Limited, Kinsale Road, Cork, Ireland \\ (Submitted 5 August 2013 - Final revision received 19 December 2013 - Accepted 6 January 2014 - First published online 20 February 2014)
}

\section{Abstract}

Different dietary fat and energy subtypes have an impact on both the metabolic health and the intestinal microbiota population of the host. The present study assessed the impact of dietary fat quality, with a focus on dietary fatty acid compositions of varying saturation, on the metabolic health status and the intestinal microbiota composition of the host. C57BL/6J mice ( $n$ 9-10 mice per group) were fed high-fat (HF) diets containing either (1) palm oil, (2) olive oil, (3) safflower oil or (4) flaxseed/fish oil for 16 weeks and compared with mice fed low-fat (LF) diets supplemented with either high maize starch or high sucrose. Tissue fatty acid compositions were assessed by GLC, and the impact of the diet on host intestinal microbiota populations was investigated using high-throughput 16S rRNA sequencing. Compositional sequencing analysis revealed that dietary palm oil supplementation resulted in significantly lower populations of Bacteroidetes at the phylum level compared with dietary olive oil supplementation $(P<0.05)$. Dietary supplementation with olive oil was associated with an increase in the population of the family Bacteroidaceae compared with dietary supplementation of palm oil, flaxseed/fish oil and high sucrose $(P<0.05)$. Ingestion of the HF-flaxseed/fish oil diet for 16 weeks led to significantly increased tissue concentrations of EPA, docosapentaenoic acid and DHA compared with ingestion of all the other diets $(P<0 \cdot 05)$; furthermore, the diet significantly increased the intestinal population of Bifidobacterium at the genus level compared with the LF-high-maize starch diet $(P<0 \cdot 05)$. These data indicate that both the quantity and quality of fat have an impact on host physiology with further downstream alterations to the intestinal microbiota population, with a HF diet supplemented with flaxseed/fish oil positively shaping the host microbial ecosystem.

\section{Key words: Dietary fatty acids: Metabolic health: Intestinal microbiota}

Excessive dietary intakes of refined carbohydrates and fat strongly correlate with weight gain, obesity and associated metabolic diseases ${ }^{(1)}$, while also influencing the intestinal microbiota composition of the host ${ }^{(2-5)}$. The human intestine harbours trillions of micro-organisms, containing over 100-fold more genes than the host genome, whereby the collective genome of these micro-organisms has co-evolved with the host and contributes to biochemical and metabolic functions that the host could not otherwise perform ${ }^{(6-8)}$.

Recent advances in non-culture-based analysis, such as $16 \mathrm{~S}$ rRNA sequencing technology, have provided extensive data in relation to the microbial composition of an ecosystem. Briefly, the 16S rRNA gene has been most frequently targeted as a means of identifying the microbial composition of an ecosystem due to its presence in all prokaryotes and the existence of variable domains that allow different taxa to be distinguished $^{(9)}$. Such technology has revealed clear alterations in the intestinal microbiota of obese mouse models ${ }^{(10)}$ and human subjects ${ }^{(6)}$, compared with their lean counterparts. The obese phenotype harbours a gut microbial population that is capable of extracting energy efficiently from ingested food and has superior ability to produce SCFA ${ }^{(11,12)}$. Recent studies have reported the effects of specific dietary fatty acid subtypes, such as SFA, MUFA and PUFA, on metabolic parameters and intestinal microbial populations ${ }^{(13-17)}$. For example, Buettner et al. ${ }^{(13)}$ showed a reduction in liver inflammation and TAG levels following high levels of fish oil feeding, while others have demonstrated that hamsters fed a

Abbreviations: cDNA, complementary DNA; FAME, fatty acid methyl ester; Fas, fatty acid synthase; HF, high fat; LF, low fat; Srebp-1c, sterol regulatory element-binding protein-1c.

*Corresponding authors: Professor C. Stanton, email catherine.stanton@teagasc.ie; Professor R. M. O’ Doherty, email rmo1@pitt.edu 
low-MUFA diet with a low ratio of PUFA:SFA exhibited increased weight gain and body fat accumulation ${ }^{(14)}$. Furthermore, while a diverse intestinal microbiota is preferable, ingestion of a high-fat diet containing palm oil has been reported to decrease bacterial diversity ${ }^{(15,16)}$. While some studies have shown that subtle alterations caused by the ingestion of different dietary fatty acid subtypes indeed have an impact on the intestinal microbiota, the major difficulty arises in linking these changes in the microbiota to the metabolic health status of the host. Potential mechanisms that link how the diet alters the intestinal microbiota have been suggested, such as through changes to lipid metabolism-related genes in the distal small intestine or through changes in host bile composition caused by the diet ${ }^{(15,17,18)}$; however, it is imperative to further understand the influence that different fat qualities, as opposed to quantities and energy types, have on the intestinal microbiota for the future prevention of obesity.

Therefore, the aims of the present study were to investigate how different qualities of fat in the diet, achieved through altering dietary fatty acid compositions and different sources of energy in the diet, have an impact on the metabolic health status of the host, and furthermore, to investigate the influence of diets on the delicate nature of host intestinal microbiota composition by employing $16 \mathrm{~S}$ rRNA sequencing technology. For this purpose, mice were fed high-fat (HF, $45 \%$ energy from fat) diets containing either (1) palm oil (mainly SFA), (2) olive oil (MUFA), (3) safflower oil ( $n$-6 PUFA) or (4) flaxseed/fish oil ( $n$-3 PUFA). In parallel, to investigate metabolic parameters and the intestinal microbiota composition of the host, mice were fed low-fat (LF) diets rich in either maize starch (12\% energy from fat and $41 \%$ maize starch) or sucrose (12\% energy from fat and 65\% sucrose) for 16 weeks.

\section{Materials and methods}

\section{Animals and diets}

Wild-type C57BL/6J male mice (21 d old) were obtained from Harlan Limited and housed under barrier-maintained conditions within the Biological Services Unit, Teagasc, Moorepark. All experiments involving animals were approved by the University College Cork Animal Ethics Committee, and experimental procedures were conducted under appropriate license from the Irish Government in compliance with the institutional and national guidelines for the care and use of animals. Mice were allowed to acclimatise for 5 weeks before the commencement of the experiments, and were subsequently randomly divided into the following six dietary groups ( $n$ 9-10 mice per group): (1) LF-high-maize starch diet (12\% energy from fat and $41 \%$ maize starch; $n$ 10); (2) LF-high-sucrose diet (12\% energy from fat and $65 \%$ sucrose; $n$ 10); (3) HF-palm oil (mainly SFA) diet ( $45 \%$ energy from fat; $n$ 10); (4) HF-olive oil (extra-virgin) (MUFA) diet (45\% energy from fat; $n$ 9); (5) HF-safflower oil ( $n$-6 PUFA) diet (45\% energy from fat; $n$ 10); (6) HF-flaxseed/fish oil ( $n$-3 PUFA) diet ( $45 \%$ energy from fat; $n$ )). Mice were housed in groups of four to five per cage with two cages per dietary treatment group, allowed free access to food and water at all times and maintained under a $12 \mathrm{~h}$ light $-12 \mathrm{~h}$ dark cycle. All diets were supplied by Harlan Limited. Fatty acid compositions of the experimental diets are shown in Table 1. Body weight and food intake were recorded weekly. Following 16 weeks of dietary treatment, fat and lean body mass were measured using a Minispec mq benchtop NMR spectrometer (Bruker Instruments), and mice were killed by cervical dislocation. Liver, brain, fat pads (epididymal, perirenal, mesenteric and subcutaneous) and caecal

Table 1. Dietary components and fatty acid compositions of experimental oils

\begin{tabular}{|c|c|c|c|c|c|c|}
\hline & LF-high maize starch & LF-high sucrose & HF-palm oil & HF-olive oil & HF-safflower oil & HF-flaxseed/fish oil \\
\hline \multicolumn{7}{|l|}{$\mathrm{g} / \mathrm{kg}$} \\
\hline Casein & $192 \cdot 0$ & $192 \cdot 0$ & $230 \cdot 0$ & $230 \cdot 0$ & $230 \cdot 0$ & $230 \cdot 0$ \\
\hline DL-Met & 3.0 & 3.0 & 3.0 & 3.0 & 3.0 & 3.0 \\
\hline Sucrose & $120 \cdot 0$ & $645 \cdot 0$ & $65 \cdot 0$ & $65 \cdot 0$ & $65 \cdot 0$ & $65 \cdot 0$ \\
\hline Maize starch & 411.0 & & $213 \cdot 4$ & $213 \cdot 4$ & $213 \cdot 4$ & 213.4 \\
\hline Maltodextrin & $150 \cdot 0$ & & $150 \cdot 0$ & $150 \cdot 0$ & $150 \cdot 0$ & $150 \cdot 0$ \\
\hline Palm oil & 12.5 & $12 \cdot 5$ & $225 \cdot 0$ & & & \\
\hline Olive oil & $12 \cdot 5$ & $12 \cdot 5$ & & $225 \cdot 0$ & & \\
\hline Safflower oil & 12.5 & 12.5 & & & $225 \cdot 0$ & \\
\hline Flaxseed oil & 6.25 & $6 \cdot 25$ & & & & 112.5 \\
\hline Fish oil & $6 \cdot 25$ & $6 \cdot 25$ & & & & $112 \cdot 5$ \\
\hline Mineral mix & 35.0 & $35 \cdot 0$ & $42 \cdot 0$ & $42 \cdot 0$ & $42 \cdot 0$ & $42 \cdot 0$ \\
\hline Calcium phosphate & 1.4 & 1.4 & 1.5 & 1.5 & 1.5 & 1.5 \\
\hline Cellulose & $20 \cdot 08$ & $56 \cdot 08$ & $50 \cdot 0$ & $50 \cdot 0$ & $50 \cdot 0$ & $50 \cdot 0$ \\
\hline Vitamin mix & $15 \cdot 0$ & $15 \cdot 0$ & $17 \cdot 0$ & $17 \cdot 0$ & $17 \cdot 0$ & $17 \cdot 0$ \\
\hline Choline bitartrate & 2.5 & 2.5 & 3.0 & 3.0 & $3 \cdot 0$ & 3.0 \\
\hline tert-Butyhydraquinone & 0.02 & 0.02 & 0.1 & $0 \cdot 1$ & 0.1 & 0.1 \\
\hline \multicolumn{7}{|l|}{$\%$ of total fat } \\
\hline Palmitic acid & $19 \cdot 4$ & $19 \cdot 4$ & $45 \cdot 0$ & $13 \cdot 8$ & $6 \cdot 7$ & $10 \cdot 8$ \\
\hline Stearic acid & 3.6 & 3.6 & 4.8 & $2 \cdot 6$ & 2.5 & 3.4 \\
\hline Oleic acid & 33.9 & 33.9 & 38.5 & 70.5 & $13 \cdot 2$ & $14 \cdot 8$ \\
\hline Linoleic acid & $25 \cdot 6$ & $25 \cdot 6$ & $9 \cdot 3$ & 9.9 & $77 \cdot 1$ & 8.4 \\
\hline Linolenic acid & $7 \cdot 1$ & $7 \cdot 1$ & 0.3 & 0.6 & & $28 \cdot 2$ \\
\hline EPA & $1 \cdot 7$ & $1 \cdot 7$ & & & & $6 \cdot 9$ \\
\hline DHA & 1.3 & 1.3 & & & & $5 \cdot 4$ \\
\hline
\end{tabular}

LF, low fat; HF, high fat. 
contents were removed, blotted dry on filter paper, weighed and flash-frozen immediately in liquid $\mathrm{N}_{2}$. Blood samples were collected from fasted animals and allowed to clot for at least $30 \mathrm{~min}$ at $4^{\circ} \mathrm{C}$ before centrifugation at $2000 \mathrm{~g}$ for $20 \mathrm{~min}$. All samples were stored at $-80^{\circ} \mathrm{C}$ until processed.

\section{Biochemical markers and measurements of plasma variables}

Blood glucose was determined using a Contour glucose meter and blood glucose strips. Plasma insulin and leptin concentrations were measured using the Ultra Sensitive Mouse Insulin ELISA Kit (Crystal Chem, Inc.) and the Mouse Leptin ELISA Kit (Crystal Chem, Inc.), according to the manufacturer's instructions. Plasma NEFA levels were determined using the commercial NEFA-HR(2) kit (Wako Diagnostics), and plasma TAG levels were measured using Infinity Triglyceride Liquid Stable Reagent (Thermo Scientific).

\section{Determination of liver TAG levels}

Lipids from $50 \mathrm{mg}$ of frozen liver were extracted and purified according to the method of Folch ${ }^{(19)}$. Liver lipids were extracted using chloroform-methanol (2:1, v/v; Thermo Scientific) and an aliquot of the organic phase was collected, dried and resuspended in Infinity Triglyceride Liquid Stable Reagent (Thermo Scientific). All samples and standards were analysed in duplicate, and TAG content was determined as described previously ${ }^{(10)}$.

\section{RNA extraction and complementary DNA synthesis}

Total RNA was isolated from liver tissue using the commercial RNeasy mini kit (Qiagen), according to the manufacturer's instructions, and quantified using the Nanodrop (Thermo Scientific). Single-stranded complementary DNA (cDNA) was synthesised from $1 \mu \mathrm{g}$ of total RNA using $2.5 \mathrm{ng} / \mu \mathrm{l}$ of random primers (Promega), $10 \mathrm{~mm}-\mathrm{PCR}$ nucleotide mix (Promega), 40 units/ $\mu$ l of RNasin Plus RNase Inhibitor (Promega) and Im-Prom II reverse transcriptase (Promega), according to the manufacturer's instructions.

\section{Real-time PCR analysis}

Amplification of generated cDNA was performed in the LightCycler 480 System (Roche Diagnostics Limited) using $0 \cdot 25 \mu \mathrm{M}$-primers (Eurofins MWG Operon), $1 \mu \mathrm{l} \mathrm{cDNA}$ and the LightCycler 480 SYBR Green I Master Kit (Roche Diagnostics Limited), according to the manufacturer's instructions. Realtime PCR conditions were set at $95^{\circ} \mathrm{C}$ for $10 \mathrm{~min}$ followed by fifty cycles at $95^{\circ} \mathrm{C}$ for $10 \mathrm{~s}, 60^{\circ} \mathrm{C}$ for $5 \mathrm{~s}$ and $72^{\circ} \mathrm{C}$ for $15 \mathrm{~s}$. Specific forward and reverse primers used to amplify cDNA were newly designed and are listed as follows: fatty acid synthase (Fas) cDNA: forward 5'-GGCCACCTCAGTCCTTGATATCATG- $3^{\prime}$ and reverse $5^{\prime}$-GCCCGCGAACCACTAACGAG- $3^{\prime}$; sterol regulatory element-binding protein-1c (Srebp-1c) CDNA: forward $5^{\prime}$-CTCCAGCTCATCAACAACCAAGAC- $3^{\prime}$ and reverse $\quad 5^{\prime}$-AGAGGAGGCCAGAGAAGCAGAAGA-3'; PPAR $\alpha$
cDNA: forward 5'-ATGGGGGTGATCGGAGGCTAATAG- $3^{\prime}$ and reverse 5'-GGGTGGCAGGAAGGGAACAGAC- $3^{\prime}$; PPAR $\gamma$ CDNA: forward $5^{\prime}$-TCAGGTTTGGGCGGATGC- $3^{\prime}$ and reverse $5^{\prime}$-TCAGCGGGAAGGACTTTATGTATG- $3^{\prime}$. All samples were analysed in duplicate and normalised to $\beta$-actin as a constitutively expressed control gene: forward 5'-AGAGGGAAATCGTGCGTGAC-3' and reverse, $5^{\prime}$-CAATAGTGATGACCTGGCGT-3'. Melting curve analysis allowed validation of the authenticity of real-time PCR products. Basic relative quantification of expression was determined using the comparative $2^{-\Delta \Delta C_{\mathrm{t}}}$ method.

\section{Lipid extraction and fatty acid analysis}

Lipids were extracted and purified with chloroform-methanol (2:1, v/v; Thermo Scientific) according to the method of Folch $^{(19)}$. Fatty acid methyl esters (FAME) were prepared using first $10 \mathrm{ml}$ of $0.5 \mathrm{~m} \mathrm{NaOH}$ (Sigma) in methanol for $10 \mathrm{~min}$ at $90^{\circ} \mathrm{C}$ followed by $10 \mathrm{ml}$ of $14 \% \mathrm{BF}_{3}$ in methanol (Sigma) for $10 \mathrm{~min}$ at $90^{\circ} \mathrm{C}^{(20)}$. FAME were recovered with hexane (Fisher Scientific). Before GLC analysis, samples were dried over $0.5 \mathrm{~g}$ anhydrous sodium sulphate (Sigma) for $1 \mathrm{~h}$ and stored at $-20^{\circ} \mathrm{C}$. FAME were separated by GLC (Varian 3400; JVA Analytical) fitted with a flame ionisation detector using a Chrompack CP Sil 88 column $(100 \mathrm{~m} \times 0.25 \mathrm{~mm}$ internal diameter and $0.20 \mu \mathrm{m}$ film thickness, Chrompack; JVA Analytical) and $\mathrm{He}$ as a carrier gas. The column oven was programmed initially at $80^{\circ} \mathrm{C}$ for $8 \mathrm{~min}$ and then increased by $8.5^{\circ} \mathrm{C} / \mathrm{min}$ to a final column temperature of $200^{\circ} \mathrm{C}$. The injection volume used was $0.6 \mu \mathrm{l}$, with an automatic sample injection on a SPI 1093 splitless on-column temperature-programmable injector. Peaks were integrated by using the Varian Star Chromatography Workstation version 6.0 software, and were identified by comparison of retention times with pure FAME standards (Nu-Chek Prep). The percentage of individual fatty acids was calculated according to the peak areas relative to the total area (total fatty acids were set at $100 \%$ ). All fatty acid data are presented as means with their standard errors in g/100 g FAME.

\section{SCFA analysis}

Approximately $100 \mathrm{mg}$ of caecal contents were vortex-mixed with $1.0 \mathrm{ml}$ Milli-Q water and after standing for $10 \mathrm{~min}$ at room temperature, the contents were centrifuged at $10000 \mathrm{~g}$ for 5 min to pellet bacteria and other solids. A supernatant fluid was obtained, to which $3.0 \mathrm{~mm}$-2-ethylbutyric acid (Sigma) was added as an internal standard, and the samples were filtered before being transferred to clean vials. Standard solutions containing $10 \cdot 0,8 \cdot 0,6 \cdot 0,4 \cdot 0,2 \cdot 0,1 \cdot 0$ and $0.5 \mathrm{mmol} / 1$ of acetic acid, propionic acid, isobutyric acid and butyric acid (Sigma), respectively, were used for calibration. The concentration of SCFA was measured using a Varian 3500 GC flame ionisation system, fitted with a Nukol-FFAP column $(30 \mathrm{~m} \times 0.32 \mathrm{~mm}$ $\times 0.25 \mu \mathrm{m}$; Sigma). He gas was used as a carrier at a flow rate of $1.3 \mathrm{ml} / \mathrm{min}$. The initial oven temperature was $100^{\circ} \mathrm{C}$ for $0.5 \mathrm{~min}$, raised to $180^{\circ} \mathrm{C}$ at $8^{\circ} \mathrm{C} / \mathrm{min}$ and held for $1 \mathrm{~min}$, then increased to $200^{\circ} \mathrm{C}$ at $20^{\circ} \mathrm{C} / \mathrm{min}$, and finally held at $200^{\circ} \mathrm{C}$ for $5 \mathrm{~min}$. The temperatures of the detector and injector were set 
at 250 and $240^{\circ} \mathrm{C}$, respectively. Peaks were integrated by using the Varian Star Chromatography Workstation version 6.0 software. Standards were included in each run to maintain calibration.

\section{DNA extraction and pyrosequencing}

Total DNA was extracted from the caecal contents of all mice using the QIAamp DNA Stool Mini Kit (Qiagen), coupled with an initial bead-beating step. Universal 16S rRNA primers, designed to amplify from highly conserved regions corresponding to those flanking the V4 region, as described previously ${ }^{(10)}$, were used for Taq-based PCR amplification. Sequencing was performed on a Roche 454 GS-FLX using Titanium chemistry within the Teagasc 454 Sequencing Platform. Raw sequences were quality trimmed using the Qiime Suite of programmes ${ }^{(21)}$; any reads not meeting the quality criteria of a minimum quality score of 25 and a sequence length shorter than $150 \mathrm{bp}$ for $16 \mathrm{~S}$ amplicon reads were discarded. Trimmed FASTA sequences were then BLASTed ${ }^{(22)}$ against a previously published 16Sspecific database ${ }^{(23)}$ using default parameters. The resulting BLAST output was parsed using MEGAN ${ }^{(24)}$. MEGAN assigns reads to NCBI taxonomies by using the Lowest Common Ancestor algorithm. Bit scores were used from within MEGAN for filtering the results before tree construction and summarisation. A bit score of 86 was selected as previously used for $16 \mathrm{~S}$ ribosomal sequence data ${ }^{(23)}$. Phylum and family counts for each subject were extracted from MEGAN. Sequences were clustered into operational taxonomical units, chimera checked and aligned using the default pipeline within Qiime, and subsequently $\alpha$ and $\beta$ diversities were generated. A phylogenetic tree was calculated using the FastTree software (doi:10.1093/ molbev/msp077). The resulting principal coordinate analysis was visualised within KiNG.

\section{Statistical analysis}

All results are presented as means with their standard errors (per group). To assess whether differences between the treatment groups were significant, data were analysed using one-way ANOVA followed by post hoc Tukey's multiple comparison test using GraphPad Prism version 4.0 for Windows
(GraphPad Software). Compositional data were statistically analysed using Minitab release 15.1.1.0 (www.minitab.com). A non-parametric Kruskal-Wallis test was used to estimate the relationships between the different dietary groups. Statistical significance was accepted at $P<0 \cdot 05$.

\section{Results}

Effect of varying dietary fatty acid compositions on weight gain, body composition and host fat storage

A higher percentage of weight gain was observed in the group fed the HF-palm oil diet for 16 weeks compared with the HFolive oil $(P<0.05)$ - and LF-high sucrose $(P<0.05)$-fed groups, despite no differences in cumulative energy intake between these groups (Table 2). Furthermore, subcutaneous fat mass was higher following feeding of the HF-palm oil diet than after feeding of the HF-olive oil diet $(P<0.05$; Table 2$)$. The group supplemented with the HF-palm oil diet also had a higher percentage of fat mass $(P<0.05$; Fig. $1(\mathrm{~A}))$ and a lower percentage of lean mass $(P<0.05$; Fig. $1(\mathrm{~B}))$ than the HF-olive oil-fed group and both LF-high-carbohydrate-fed groups. The percentage lean mass was higher in the group fed the olive oil diet for 16 weeks than in the other HF dietfed groups $(P<0.05$; Fig. 1(B)). The percentage of weight gain was higher in the LF-high maize starch-fed group than in the LF-high sucrose-fed group $(P<0.05$; Table 2$)$, which was most probably due to the greater food intake $(P<0.05$; Table 2) and therefore greater cumulative energy intake $(P<0.05$; Table 2$)$ in the former group. Visceral fat mass was also higher in the LF-high maize starch-fed group than in the LF-high sucrose-fed group after feeding for 16 weeks $(P<0 \cdot 05$; Table 2).

Since the energy content of the LF-high-carbohydrate diets $(16 \mathrm{~kJ} / \mathrm{g})$ was only approximately $3 \mathrm{~kJ} / \mathrm{g}$ lower than that of the high-fat diets $(19 \mathrm{~kJ} / \mathrm{g})$, differences in total cumulative energy intake between the groups resulted from differences in food intake, due to dietary preference. The LF-high maize starchfed group consumed more food over the study period, resulting in a significantly higher cumulative energy intake, than the groups supplemented with the HF-safflower oil and HF-flaxseed/fish oil diets and the LF-high-sucrose diet. However, no

Table 2. Body mass, fat mass, food intake and cumulative energy intake of mice fed high-fat (HF) diets supplemented with either palm oil, olive oil, safflower oil or flaxseed/fish oil compared with those fed low-fat (LF) diets supplemented with either high sucrose or high maize starch for 16 weeks (Mean values with their standard errors; $n$ 9-10 mice per group)

\begin{tabular}{|c|c|c|c|c|c|c|c|c|c|c|c|c|}
\hline & \multicolumn{2}{|c|}{$\begin{array}{l}\text { LF-high maize } \\
\text { starch }\end{array}$} & \multicolumn{2}{|c|}{$\begin{array}{l}\text { LF-high } \\
\text { sucrose }\end{array}$} & \multicolumn{2}{|c|}{ HF-palm oil } & \multicolumn{2}{|c|}{ HF-olive oil } & \multicolumn{2}{|c|}{ HF-safflower oil } & \multicolumn{2}{|c|}{$\begin{array}{l}\text { HF-flaxseed/ } \\
\text { fish oil }\end{array}$} \\
\hline & Mean & SEM & Mean & SEM & Mean & SEM & Mean & SEM & Mean & SEM & Mean & SEM \\
\hline Initial weight (g) & 21.67 & 0.66 & 21.03 & 0.53 & $21 \cdot 8$ & 0.69 & 20.96 & 0.52 & $20 \cdot 91$ & 0.46 & 20.5 & 0.41 \\
\hline Final weight (g) & $31.00^{\mathrm{a}, \mathrm{c}}$ & 0.91 & $26 \cdot 10^{\mathrm{b}, \mathrm{d}}$ & 0.86 & $34.49^{\mathrm{a}}$ & 0.82 & $28.93^{\mathrm{c}, \mathrm{d}}$ & 1.56 & $32 \cdot 17^{\mathrm{a}, \mathrm{c}}$ & 1.5 & $31 \cdot 50^{\mathrm{a}, \mathrm{c}}$ & 0.92 \\
\hline Weight gain (\%) & $43 \cdot 35^{\mathrm{a}, \mathrm{c}}$ & 2.96 & $24 \cdot 32^{\mathrm{b}, \mathrm{d}}$ & 3.5 & $58.63^{\mathrm{a}}$ & 1.99 & $37.56^{\mathrm{c}, \mathrm{d}}$ & 5.48 & $53 \cdot 33^{\mathrm{a}, \mathrm{c}}$ & 4.85 & $53 \cdot 82^{\mathrm{a}, \mathrm{c}}$ & 4.08 \\
\hline Visceral fat mass (g) & $2 \cdot 38^{a}$ & 0.15 & $1.44^{\mathrm{b}}$ & 0.15 & $3.00^{\mathrm{a}}$ & 0.13 & $2 \cdot 18^{\mathrm{a}}$ & 0.28 & $2.91^{\mathrm{a}}$ & 0.27 & $2.56^{a}$ & 0.14 \\
\hline Subcutaneous fat mass (g) & $0.75^{a, c}$ & 0.04 & $0.47^{\mathrm{C}}$ & 0.06 & $1 \cdot 15^{\mathrm{b}}$ & 0.05 & $0 \cdot 71^{a, c}$ & $0 \cdot 11$ & $0.94^{\mathrm{a}, \mathrm{b}}$ & 0.1 & $1.03^{a, b}$ & 0.09 \\
\hline $\begin{array}{l}\text { Food intake } \\
\text { (g/d per mouse) }\end{array}$ & $3 \cdot 67^{\mathrm{a}}$ & 0.11 & $3 \cdot 25^{d}$ & 0.11 & $2 \cdot 92^{\mathrm{b}}$ & 0.06 & $2 \cdot 98^{b, d}$ & 0.09 & $2 \cdot 71^{b, c}$ & 0.06 & $2 \cdot 52^{\mathrm{c}}$ & 0.08 \\
\hline $\begin{array}{l}\text { Cumulative energy intake } \\
\text { (kJ/week per mouse) }\end{array}$ & $408 \cdot 55^{a}$ & $9 \cdot 32$ & $362 \cdot 00^{\mathrm{b}, \mathrm{c}}$ & 9.8 & $394 \cdot 23^{a, c}$ & $6 \cdot 39$ & $401 \cdot 67^{a}$ & 8.73 & $365 \cdot 49^{b, c}$ & $6 \cdot 2$ & $340 \cdot 36^{b}$ & 8.35 \\
\hline
\end{tabular}

a,b,c,d Mean values within a row with unlike superscript letters were significantly different $(P<0.05$; ANOVA followed by post hoc Tukey's multiple comparison test). 

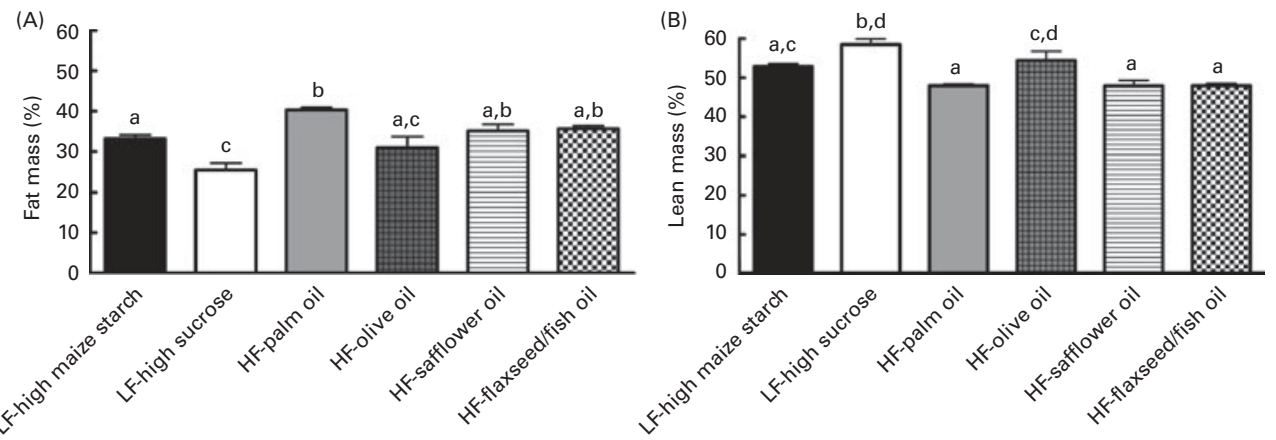

Fig. 1. (A) Body composition as determined by NMR showing the percentage of fat mass for mice fed high-fat (HF) diets supplemented with either palm oil, olive oil, safflower oil or flaxseed/fish oil compared with those fed low-fat (LF) diets supplemented with either high sucrose or high maize starch for 16 weeks. Values are means $(n 9-10)$, with their standard errors represented by vertical bars. ${ }^{a, b, c}$ Mean values with unlike letters were significantly different $(P<0.05$; ANOVA followed by post hoc Tukey's multiple comparison test). (B) Body composition as determined by NMR showing the percentage of lean mass for mice fed HF diets supplemented with either palm oil, olive oil, safflower oil or flaxseed/fish oil compared with those fed LF diets supplemented with either high sucrose or high maize starch for 16 weeks. Values are means $(n 9-10)$, with their standard errors represented by vertical bars. ${ }^{a, b, c, d}$ Mean values with unlike letters were significantly different $(P<0.05$; ANOVA followed by post hoc Tukey's multiple comparison test).

differences in the overall percentage of weight gain were observed between the groups fed the LF-high-maize starch, HF-safflower oil and HF-flaxseed/fish oil diets.

\section{Higher plasma glucose and leptin concentrations associated with saturated fat}

No differences in plasma TAG, insulin or NEFA concentrations were found between the groups following 16 weeks of dietary feeding (Table 3). Fasting glucose levels were higher in the HF-palm oil-fed group than in both the HF-safflower oiland LF-high sucrose-fed groups $(P<0 \cdot 05$; Table 3$)$, while plasma glucose concentrations were lower in the LF-high sucrose-fed group than in the groups fed the LF-high-maize starch, HF-palm oil and HF-olive oil diets $(P<0 \cdot 05$; Table 3$)$. Circulating plasma leptin concentrations were also higher in the HF-palm oil-fed group than in the HF-olive oil- and both LF-high carbohydrate-fed groups $(P<0.05$; Table 3$)$.

\section{Saturation of fat influences host liver mass, TAG levels and} hepatic gene expression

Liver tissue weight (Fig. 2(A)) and total liver TAG levels (Fig. 2(B)) were higher $(P<0.05)$ in the palm oil-fed group than in all the other dietary groups. Among the high-fat diets, as the degree of saturation shifted from the more SFA source of palm oil to the $n-3$ PUFA source of flaxseed/fish oil, the levels of liver TAG steadily decreased in a coinciding manner (Fig. 2(B)).

Briefly, the expression of certain genes related to fatty acid metabolism and inflammation in the liver was assessed in an effort to correlate their expression with liver mass and TAG levels. Hepatic expression of Fas was higher in the palm oilfed group than in the flaxseed/fish oil-fed group $(P<0.05$; see online supplementary Fig. S1). Furthermore, the olive oil-fed group had a higher hepatic expression of Fas than the flaxseed/fish oil-fed group $(P<0.05$; see online supplementary Fig. S1), while Fas expression was higher in the LF-high-maize starch-fed group than in the HF-safflower oil-, HF-flaxseed/ fish oil- and LF-high sucrose-fed groups $(P<0 \cdot 05$; see online supplementary Fig. S1). Hepatic expression of Srebp-1c was higher in the LF-high maize starch-fed group than in the highfat diet-fed groups (except the olive oil-fed group) and the LFhigh sucrose-fed group $(P<0 \cdot 05$; see online supplementary Fig. S1). Hepatic expression of PPAR $\alpha$ was reduced in all the dietary groups compared with the LF-high maize starch-fed group $(P<0.05$; see online supplementary Fig. S1), while PPAR $\alpha$ expression was higher in all the high-fat diet-fed groups than in the LF-high sucrose-fed group $(P<0.05$; see online supplementary Fig. S1).

Table 3. Plasma variables in mice fed high-fat (HF) diets supplemented with either palm oil, olive oil, safflower oil or flaxseed/fish oil compared with those fed low-fat (LF) diets supplemented with either high sucrose or high maize starch for 16 weeks*

(Mean values with their standard errors; $n$ 9-10 mice per group)

\begin{tabular}{|c|c|c|c|c|c|c|c|c|c|c|c|c|}
\hline & \multicolumn{2}{|c|}{$\begin{array}{l}\text { LF-high maize } \\
\text { starch }\end{array}$} & \multicolumn{2}{|c|}{ LF-high sucrose } & \multicolumn{2}{|c|}{ HF-palm oil } & \multicolumn{2}{|c|}{ HF-olive oil } & \multicolumn{2}{|c|}{ HF-safflower oil } & \multicolumn{2}{|c|}{$\begin{array}{l}\text { HF-flaxseed/fish } \\
\text { oil }\end{array}$} \\
\hline & Mean & SEM & Mean & SEM & Mean & SEM & Mean & SEM & Mean & SEM & Mean & SEM \\
\hline TAG (mmol/l) & 0.51 & 0.09 & 0.49 & 0.11 & 0.39 & 0.05 & 0.37 & 0.06 & 0.34 & 0.06 & 0.41 & 0.04 \\
\hline Glucose $(\mathrm{mmol} / \mathrm{l})$ & $8 \cdot 90^{a, c}$ & 0.50 & $6 \cdot 73^{\mathrm{b}}$ & 0.30 & $9 \cdot 29^{a}$ & 0.29 & $9 \cdot 11^{a}$ & 0.36 & $7 \cdot 41^{\mathrm{b}, \mathrm{c}}$ & 0.28 & $7 \cdot 86^{a, b, c}$ & 0.52 \\
\hline Insulin (ng/ml) & 0.2 & 0.04 & 0.25 & 0.06 & 0.36 & 0.06 & 0.11 & 0.03 & 0.2 & 0.07 & 0.37 & 0.11 \\
\hline Leptin (ng/ml) & $25 \cdot 4^{\mathrm{a}, \mathrm{c}}$ & 3.2 & $11 \cdot 1^{\mathrm{c}}$ & 1.9 & $44 \cdot 6^{\mathrm{b}}$ & 3.4 & $25 \cdot 0^{a, c}$ & 4.8 & $36 \cdot 8^{a, b}$ & 5.9 & $29 \cdot 5^{\mathrm{a}, \mathrm{b}}$ & 4.7 \\
\hline NEFA (mmol/l) & 0.57 & 0.06 & 0.54 & 0.08 & 0.56 & 0.05 & 0.49 & 0.05 & 0.58 & 0.05 & 0.54 & 0.08 \\
\hline
\end{tabular}

${ }^{a, b, c}$ Mean values within a row with unlike superscript letters were significantly different $(P<0.05$; ANOVA followed by post hoc Tukey's multiple comparison test) * Blood was collected after animals were fasted. 

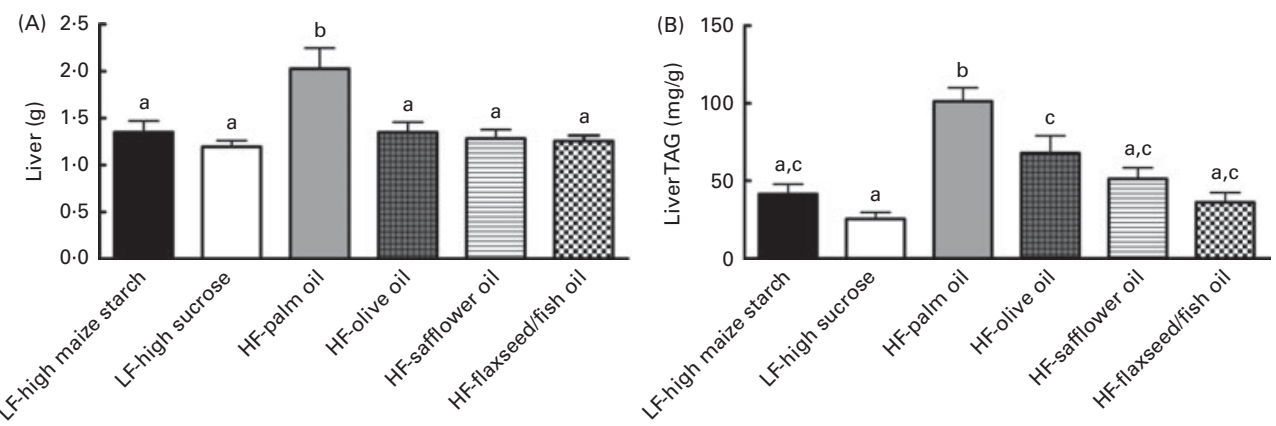

Fig. 2. (A) Total liver weight of mice fed high-fat (HF) diets supplemented with either palm oil, olive oil, safflower oil or flaxseed/fish oil compared with those fed low-fat (LF) diets supplemented with either high sucrose or high maize starch for 16 weeks. Values are means ( $n 9-10)$, with their standard errors represented by vertical bars. ${ }^{\mathrm{a}, \mathrm{b}}$ Mean values with unlike letters were significantly different $(P<0.05$; ANOVA followed by post hoc Tukey's multiple comparison test). (B) Total liver TAG levels of mice fed HF diets supplemented with either palm oil, olive oil, safflower oil or flaxseed/fish oil compared with those fed LF diets supplemented with either high sucrose or high maize starch for 16 weeks. Values are means $(n 9-10)$, with their standard errors represented by vertical bars. ${ }^{\text {,b,c }}$ Mean values with unlike letters were significantly different $(P<0.05$; ANOVA followed by post hoc Tukey's multiple comparison test).

\section{Impact of different sources of fat and energy on host tissue fatty acid compositions}

The palm oil-fed group had higher levels of palmitic acid (16:0) in the liver and brain compared with the other highfat diet-fed groups and the LF-high sucrose-fed group $(P<0.05$; Tables 4 and 6$)$, and in epididymal adipose tissue compared with all the other dietary groups $(P<0.05$; Table 5$)$. Additionally, the palm oil-fed group had higher levels of oleic acid (18: 1 cis-9) in liver $(P<0 \cdot 05$; Table 4$)$ and epididymal adipose tissue $(P<0.05$; Table 5$)$ compared with all the other dietary groups, except the olive oil-fed group, which had higher levels of oleic acid in the epididymal adipose tissue only compared with all the other diet-fed groups $(P<0.05$; Table 5). The safflower oil-fed group had higher levels of linoleic acid (18:2n-6), $\gamma$-linolenic acid (18:3n-6) and arachidonic acid $(20: 4 n-6)$ in all tissues compared with all the other diet-fed groups $(P<0 \cdot 05$; Tables $4-6)$. Both the LF-high carbohydrate-fed groups had higher levels of dihomo- $\gamma$-linolenic acid $(20: 3 n-6)$ in the brain $(P<0.05$; Table 6) and higher levels of palmitoleic acid (16:1 cis-9) in the liver $(P<0.05$; Table 4$)$ compared with all the other dietary groups. $\alpha$-Linolenic acid $(18: 3 n-3)$ levels were higher in all tissues $(P<0 \cdot 05$; Tables 4-6) of the flaxseed/fish oil-fed group than those of the other diet-fed groups, except in the brain of the LF-high sucrose-fed group. Furthermore, the flaxseed/fish oil-fed group had higher levels of EPA $(20: 5 n-3)$, docosapentaenoic acid (22:5n-3) and DHA $(22: 6 n-3)$ in all tissues $(P<0.05$; Table 4-6), lower levels of arachidonic acid in the brain $(P<0 \cdot 05$; Table 6$)$ and higher levels stearic (18:0) and myristic (14:0) acids in epididymal adipose tissue $(P<0.05$; Table 5) compared with the other dietary groups.

\section{Saturated fat is associated with higher caecal concentrations of SCFA}

The mean total concentrations of SCFA (acetate, propionate, butyrate and isobutyrate) in caecal contents were found to be highest in the palm oil-fed group compared with the

Table 4. Fatty acid profile (g/100 g FAME) in the liver of mice fed high-fat (HF) diets supplemented with either palm oil, olive oil, safflower oil or flaxseed/fish oil compared with those fed low-fat (LF) diets supplemented with either high sucrose or high maize starch for 16 weeks

(Mean values with their standard errors; $n$ 9-10 mice per group)

\begin{tabular}{|c|c|c|c|c|c|c|c|c|c|c|c|c|}
\hline \multirow[b]{2}{*}{ Fatty acids } & \multicolumn{2}{|c|}{$\begin{array}{l}\text { LF-high maize } \\
\text { starch }\end{array}$} & \multicolumn{2}{|c|}{ LF-high sucrose } & \multicolumn{2}{|c|}{ HF-palm oil } & \multicolumn{2}{|c|}{ HF-olive oil } & \multicolumn{2}{|c|}{ HF-safflower oil } & \multicolumn{2}{|c|}{$\begin{array}{l}\text { HF-flaxseed/fish } \\
\text { oil }\end{array}$} \\
\hline & Mean & SEM & Mean & SEM & Mean & SEM & Mean & SEM & Mean & SEM & Mean & SEM \\
\hline $14: 0$ & $0.51^{\mathrm{a}, \mathrm{b}}$ & 0.02 & $0.45^{\mathrm{a}, \mathrm{d}}$ & 0.02 & $0.44^{\mathrm{a}, \mathrm{d}}$ & 0.01 & $0.37^{c, d}$ & 0.01 & $0.29^{c}$ & 0.02 & $0.56^{b}$ & 0.04 \\
\hline $16: 0$ & $24 \cdot 02^{a, b}$ & 0.18 & $22 \cdot 51^{\mathrm{a}, \mathrm{d}}$ & 0.5 & $25 \cdot 02^{\mathrm{b}}$ & 0.29 & $18 \cdot 38^{c}$ & 0.28 & $19 \cdot 55^{c}$ & 0.67 & $22 \cdot 05^{d}$ & 0.33 \\
\hline $16: 1$ cis -9 & $4 \cdot 68^{a}$ & 0.18 & $4 \cdot 11^{\mathrm{a}}$ & 0.2 & $3 \cdot 24^{b}$ & 0.1 & $1.67^{c}$ & 0.1 & $1 \cdot 23^{c}$ & 0.13 & $2 \cdot 49^{d}$ & 0.1 \\
\hline $18: 0$ & $6 \cdot 83^{a}$ & 0.53 & $7 \cdot 37^{a, c}$ & 0.5 & $3 \cdot 62^{b}$ & 0.26 & $5 \cdot 12^{a, b}$ & 0.68 & $6 \cdot 51^{a}$ & 0.83 & $9 \cdot 74^{c}$ & 0.43 \\
\hline $18: 1$ cis-9 & $38.95^{\mathrm{a}}$ & 1.77 & $36 \cdot 80^{\mathrm{a}}$ & 1.79 & $51 \cdot 73^{b}$ & $1 \cdot 11$ & $56 \cdot 29^{b}$ & 1.85 & $19 \cdot 10^{c}$ & 1.86 & $15 \cdot 79^{c}$ & 0.58 \\
\hline $18: 2 n-6$ & $7 \cdot 91^{\mathrm{a}}$ & 0.47 & $8 \cdot 44^{a}$ & 0.45 & $4.46^{b}$ & 0.25 & $4 \cdot 40^{\mathrm{b}}$ & 0.32 & $34 \cdot 87^{c}$ & 0.79 & $8.58^{a}$ & 0.17 \\
\hline $18: 3 n-3$ & $0.71^{a}$ & 0.05 & $0.72^{a}$ & 0.06 & $0.03^{a}$ & 0.001 & $0 \cdot 18^{a}$ & 0.09 & $0.18^{a}$ & 0.01 & $12 \cdot 14^{\mathrm{b}}$ & 0.47 \\
\hline $18: 3 n-6$ & $0.07^{a}$ & 0.01 & $0.06^{a}$ & 0.004 & $0.07^{a}$ & 0.01 & $0.06^{\mathrm{a}}$ & 0.01 & $0.58^{b}$ & 0.02 & $0.09^{a}$ & 0.01 \\
\hline $20: 3 n-6$ & $0.76^{\mathrm{a}, \mathrm{d}}$ & 0.04 & $0.86^{d}$ & 0.05 & $0.36^{b}$ & 0.03 & $0.54^{a, b}$ & 0.07 & $1.98^{c}$ & 0.09 & $0.45^{b}$ & 0.02 \\
\hline $20: 4 n-6$ & $2 \cdot 80^{\mathrm{a}}$ & 0.23 & $3.69^{a}$ & 0.31 & $2 \cdot 29^{a}$ & 0.26 & $3.48^{\mathrm{a}}$ & 0.58 & $7 \cdot 25^{b}$ & 0.82 & $3 \cdot 36^{a}$ & 0.15 \\
\hline $20: 5 n-3$ & $0.88^{a}$ & 0.08 & $1 \cdot 10^{\mathrm{a}}$ & 0.12 & $0.01^{b}$ & 0.001 & $0.03^{b}$ & 0.004 & $0.02^{b}$ & 0.003 & $5 \cdot 10^{c}$ & 0.12 \\
\hline $22: 5 n-3$ & $0.53^{a}$ & 0.05 & $0.49^{a}$ & 0.04 & $0.01^{b}$ & 0.001 & $0.05^{b}$ & 0.01 & $0.13^{b}$ & 0.01 & $2 \cdot 27^{c}$ & 0.06 \\
\hline $22: 6 n-3$ & $4 \cdot 87^{a}$ & 0.5 & $5 \cdot 60^{a}$ & 0.47 & $0.42^{b}$ & 0.04 & $1 \cdot 78^{b}$ & 0.3 & $1 \cdot 81^{b}$ & 0.3 & $12 \cdot 77^{c}$ & 0.37 \\
\hline Others & $5 \cdot 60^{\mathrm{a}}$ & 0.17 & $6 \cdot 73^{c}$ & 0.17 & $6 \cdot 50^{c, d}$ & 0.29 & $6 \cdot 22^{\mathrm{a}, \mathrm{c}}$ & 0.17 & $5 \cdot 86^{a, d}$ & $0 \cdot 21$ & $3.84^{b}$ & 0.17 \\
\hline
\end{tabular}

FAME, fatty acid methyl ester.

${ }_{\mathrm{a}, \mathrm{b}, \mathrm{c}, \mathrm{d}}$ Mean values within a row with unlike superscript letters were significantly different $(P<0 \cdot 05$; ANOVA followed by post hoc Tukey's multiple comparison test). 
Table 5. Fatty acid profile ( $\mathrm{g} / 100 \mathrm{~g}$ FAME) in the epididymal adipose tissue of mice fed high-fat (HF) diets supplemented with either palm oil, olive oil, safflower oil or flaxseed/fish oil compared with those fed low-fat (LF) diets supplemented with either high sucrose or high maize starch for 16 weeks (Mean values with their standard errors; $n 9-10$ mice per group)

\begin{tabular}{|c|c|c|c|c|c|c|c|c|c|c|c|c|}
\hline \multirow[b]{2}{*}{ Fatty acids } & \multicolumn{2}{|c|}{$\begin{array}{l}\text { LF-high maize } \\
\text { starch }\end{array}$} & \multicolumn{2}{|c|}{ LF-high sucrose } & \multicolumn{2}{|c|}{ HF-palm oil } & \multicolumn{2}{|c|}{ HF-olive oil } & \multicolumn{2}{|c|}{ HF-safflower oil } & \multicolumn{2}{|c|}{$\begin{array}{l}\text { HF-flaxseed/fish } \\
\text { oil }\end{array}$} \\
\hline & Mean & SEM & Mean & SEM & Mean & SEM & Mean & SEM & Mean & SEM & Mean & SEM \\
\hline $14: 0$ & $1.01^{\mathrm{a}}$ & 0.03 & $1.20^{f}$ & 0.02 & $0.68^{b}$ & 0.02 & $0.38^{c}$ & 0.01 & $0.46^{c, d}$ & 0.02 & $2 \cdot 47^{\mathrm{e}}$ & 0.06 \\
\hline $16: 0$ & $20.04^{\mathrm{a}}$ & 0.44 & $19 \cdot 02^{\mathrm{a}}$ & $0 \cdot 16$ & $22 \cdot 35^{\mathrm{b}}$ & 0.3 & $10 \cdot 42^{c}$ & 0.2 & $11.54^{\mathrm{c}, \mathrm{d}}$ & 0.22 & $20 \cdot 14^{\mathrm{a}}$ & 0.25 \\
\hline $16: 1$ cis- 9 & $7 \cdot 28^{\mathrm{a}}$ & 0.21 & $8.53^{\mathrm{d}}$ & 0.19 & $7 \cdot 08^{a, c}$ & 0.26 & $3.01^{\mathrm{b}}$ & 0.14 & $2 \cdot 60^{\mathrm{b}}$ & 0.28 & $6 \cdot 13^{\mathrm{c}}$ & 0.26 \\
\hline $18: 0$ & $1.65^{a}$ & 0.06 & $1.35^{\mathrm{b}}$ & 0.03 & $1.35^{\mathrm{b}}$ & 0.02 & $1 \cdot 28^{\mathrm{b}}$ & 0.05 & $1.69^{\mathrm{a}}$ & 0.09 & $3.04^{c}$ & 0.06 \\
\hline $18: 1$ cis-9 & $48 \cdot 40^{\mathrm{a}}$ & 0.67 & $49 \cdot 12^{\mathrm{a}}$ & 0.5 & $55 \cdot 21^{\mathrm{b}}$ & 0.48 & $74.55^{\mathrm{c}}$ & 0.39 & $22 \cdot 57^{d}$ & 0.25 & $27.95^{\mathrm{e}}$ & 0.31 \\
\hline $18: 2 n-6$ & $13 \cdot 13^{a}$ & 0.16 & $12 \cdot 43^{\mathrm{a}}$ & 0.25 & $8 \cdot 29^{b}$ & 0.15 & $5 \cdot 63^{\mathrm{c}}$ & 0.12 & $56 \cdot 27^{d}$ & 0.43 & $12 \cdot 22^{\mathrm{a}}$ & 0.14 \\
\hline $18: 3 n-3$ & $1.45^{\mathrm{a}}$ & 0.05 & $1 \cdot 61^{\mathrm{a}}$ & 0.07 & $0 \cdot 10^{\mathrm{b}}$ & 0.01 & $0.22^{\mathrm{b}}$ & 0.01 & $0.35^{\mathrm{b}}$ & 0.02 & $17 \cdot 51^{\mathrm{c}}$ & 0.26 \\
\hline $18: 3 n-6$ & $0.03^{a}$ & 0.001 & $0.03^{a}$ & 0.001 & $0.02^{a, c}$ & 0.001 & $0.01^{b, c}$ & 0.004 & $0 \cdot 10^{d}$ & 0.01 & $0.07^{\mathrm{e}}$ & 0.003 \\
\hline $20: 3 n-6$ & $0.12^{\mathrm{a}}$ & 0.003 & $0.12^{\mathrm{a}}$ & 0.003 & $0.09^{b, d}$ & 0.003 & $0.08^{\mathrm{b}}$ & 0.001 & $0.39^{c}$ & 0.02 & $0 \cdot 12^{\mathrm{a}, \mathrm{d}}$ & 0.002 \\
\hline $20: 4 n-6$ & $0 \cdot 16^{\mathrm{a}}$ & 0.01 & $0 \cdot 17^{a}$ & 0.006 & $0.23^{\mathrm{a}}$ & 0.01 & $0.19^{a}$ & 0.01 & $0.62^{\mathrm{b}}$ & 0.04 & $0.39^{c}$ & 0.01 \\
\hline $20: 5 n-3$ & $0 \cdot 10^{\mathrm{a}}$ & 0.01 & $0.11^{\mathrm{a}}$ & 0.005 & \multicolumn{2}{|c|}{ ND } & \multicolumn{2}{|c|}{ ND } & \multicolumn{2}{|c|}{ ND } & $0.98^{\mathrm{c}}$ & 0.05 \\
\hline $22: 5 n-3$ & $0.14^{\mathrm{a}}$ & 0.01 & $0 \cdot 15^{\mathrm{a}}$ & 0.004 & \multicolumn{2}{|c|}{ ND } & & & \multicolumn{2}{|c|}{ ND } & $0.63^{c}$ & 0.02 \\
\hline $22: 6 n-3$ & $0.35^{\mathrm{a}}$ & 0.03 & $0.38^{a}$ & 0.02 & \multicolumn{2}{|c|}{ ND } & $0.06^{b}$ & 0.01 & $0.06^{b}$ & 0.004 & $1.94^{\mathrm{C}}$ & 0.06 \\
\hline Others & $6 \cdot 16^{a}$ & 0.10 & $4.95^{d}$ & 0.15 & $3.43^{b}$ & 0.10 & $3.49^{b}$ & 0.10 & $2 \cdot 44^{\mathrm{c}}$ & $0 \cdot 10$ & $3.79^{b}$ & 0.15 \\
\hline
\end{tabular}

FAME, fatty acid methyl ester; ND, not detected

$\mathrm{a}, \mathrm{b}, \mathrm{c}, \mathrm{d}, \mathrm{e}, \mathrm{f}$ Mean values within a row with unlike superscript letters were significantly different $(P<0.05$; ANOVA followed by post hoc Tukey's multiple comparison test).

other dietary groups $(P<0.05$; Table 7$)$. Of these SCFA, the concentrations of propionate, butyrate and isobutyrate were found to be higher in the palm oil-fed group than in the other diet-fed groups $(P<0.05$; Table 7$)$, while the concentration of acetate was found to be higher in the palm oil-fed group compared with the other diet-fed groups $(P<0.05$; Table 7), except the LF-high maize starch-fed group.

\section{Fat and energy sources influence differently on the composition of the intestinal microbiota}

The microbial composition in the caecal contents of individual mice was elucidated through high-throughput DNA sequencing (Roche 454-Titanium) of 16S rRNA (V4) amplicons after 16 weeks of dietary intervention. A total of 355743 reads were sequenced, corresponding to an average of 6134 reads/ mouse. Of these reads, 318586 (89\%) were assigned at the phylum level, $285224(80 \%)$ at the family level and 180584 (51\%) at the genus level. At the $97 \%$ similarity level, a total of five measures were used to indicate sufficient sampling for all the groups. Estimations for species richness, coverage and diversity were calculated for each dataset (see online supplementary Figs. S2-S6). All measures showed a high level of overall diversity within all samples, and rarefraction curves for each group indicated a sufficient depth of sequencing. For the Chao1- $\alpha$ diversity metric (see online supplementary Fig. S2), olive oil and flaxseed/fish oil feeding resulted in the least and most diverse intestinal microbiota, respectively. This trend is somewhat reflected in all the other diversity metrics (see online supplementary Figs. S3-S6). Furthermore, all diets

Table 6. Fatty acid profile (g/100 g FAME) in the brain of mice fed high-fat (HF) diets supplemented with either palm oil, olive oil, safflower oil or flaxseed/fish oil compared with those fed low-fat (LF) diets supplemented with either high sucrose or high maize starch for 16 weeks

(Mean values with their standard errors; $n$ 9-10 mice per group)

\begin{tabular}{|c|c|c|c|c|c|c|c|c|c|c|c|c|}
\hline \multirow[b]{2}{*}{ Fatty acids } & \multicolumn{2}{|c|}{$\begin{array}{l}\text { LF-high maize } \\
\text { starch }\end{array}$} & \multicolumn{2}{|c|}{ LF-high sucrose } & \multicolumn{2}{|c|}{ HF-palm oil } & \multicolumn{2}{|c|}{ HF-olive oil } & \multicolumn{2}{|c|}{ HF-safflower oil } & \multicolumn{2}{|c|}{$\begin{array}{l}\text { HF-flaxseed/fish } \\
\text { oil }\end{array}$} \\
\hline & Mean & SEM & Mean & SEM & Mean & SEM & Mean & SEM & Mean & SEM & Mean & SEM \\
\hline $14: 0$ & $0.57^{a}$ & 0.07 & $0.19^{b}$ & 0.03 & $0.18^{b}$ & 0.02 & $0.12^{b}$ & 0.002 & $0.12^{b}$ & 0.01 & $0.25^{b}$ & 0.04 \\
\hline $16: 0$ & $24 \cdot 31^{a}$ & 0.28 & $22 \cdot 18^{b, c}$ & 0.11 & $23 \cdot 84^{a}$ & 0.15 & $22 \cdot 21^{\mathrm{b}, \mathrm{c}}$ & 0.13 & $21 \cdot 78^{b}$ & 0.17 & $22 \cdot 84^{c}$ & 0.17 \\
\hline $16: 1$ cis-9 & $1 \cdot 18^{a}$ & 0.07 & $0.78^{\mathrm{d}, \mathrm{e}}$ & 0.1 & $0.75^{\mathrm{b}, \mathrm{d}}$ & 0.03 & $0.49^{\mathrm{b}, \mathrm{d}}$ & 0.01 & $0.49^{c}$ & 0.02 & $0.82^{\mathrm{d}, \mathrm{e}}$ & 0.07 \\
\hline $18: 0$ & $20 \cdot 95^{a}$ & 0.18 & $21 \cdot 59^{a, c}$ & 0.31 & $21 \cdot 20^{a, c}$ & 0.17 & $21 \cdot 99^{b, c}$ & 0.15 & $21 \cdot 59^{a, c}$ & 0.22 & $21 \cdot 67^{\mathrm{a}, \mathrm{c}}$ & 0.25 \\
\hline $18: 1$ cis-9 & $19 \cdot 27^{\mathrm{a}, \mathrm{c}, \mathrm{d}}$ & 0.31 & $20 \cdot 41^{d}$ & 0.37 & $19 \cdot 00^{c}$ & 0.27 & $20 \cdot 29^{a, d}$ & 0.35 & $17.53^{b}$ & 0.16 & $19 \cdot 99^{a, c}$ & 0.26 \\
\hline $18: 2 n-6$ & $0.56^{a}$ & 0.04 & $0.64^{a}$ & 0.15 & $0.49^{a}$ & 0.04 & $0.39^{a}$ & 0.03 & $1.95^{\mathrm{b}}$ & 0.22 & $0.73^{a}$ & 0.16 \\
\hline $18: 3 n-3$ & $0.09^{a}$ & 0.02 & $0 \cdot 20^{a, b}$ & 0.15 & $0.05^{a}$ & 0.004 & $0.04^{a}$ & 0.001 & $0.02^{\mathrm{a}}$ & 0.002 & $0.60^{b}$ & 0.23 \\
\hline $18: 3 n-6$ & ND & & ND & & ND & & ND & & ND & & ND & \\
\hline $20: 3 n-6$ & $0.52^{a}$ & 0.01 & $0.51^{a}$ & 0.01 & $0.26^{b}$ & 0.002 & $0.33^{c}$ & 0.01 & $0.39^{d}$ & 0.01 & $0.36^{\mathrm{e}}$ & 0.004 \\
\hline $20: 4 n-6$ & $6 \cdot 97^{a}$ & 0.21 & $7 \cdot 39^{a}$ & 0.21 & $8 \cdot 84^{b}$ & 0.09 & $8 \cdot 71^{b}$ & 0.09 & $8.96^{b}$ & 0.08 & $6 \cdot 15^{c}$ & 0.09 \\
\hline $20: 5 n-3$ & $0 \cdot 10^{\mathrm{a}}$ & 0.004 & $0 \cdot 10^{a}$ & 0.01 & $0.01^{b}$ & 0.001 & $0.01^{b}$ & 0.001 & $0.01^{b}$ & 0.002 & $0.42^{\mathrm{C}}$ & 0.01 \\
\hline $22: 5 n-3$ & $0.29^{a}$ & 0.01 & $0.29^{a}$ & 0.01 & $0.05^{\mathrm{b}}$ & 0.001 & $0.10^{\mathrm{C}}$ & 0.003 & $0.07^{\mathrm{b}}$ & 0.001 & $0.77^{d}$ & 0.01 \\
\hline $22: 6 n-3$ & $13 \cdot 44^{a}$ & 0.3 & $13 \cdot 79^{a}$ & 0.28 & $11 \cdot 88^{\mathrm{b}}$ & 0.1 & $13 \cdot 26^{a}$ & 0.14 & $12 \cdot 12^{b}$ & 0.12 & $15 \cdot 26^{c}$ & 0.19 \\
\hline Others & $9 \cdot 95^{a}$ & 0.39 & $10 \cdot 22^{a}$ & 0.31 & $11.65^{b}$ & 0.10 & $10 \cdot 30^{\mathrm{a}, \mathrm{d}}$ & 0.11 & $11 \cdot 28^{b, d}$ & 0.22 & $8.48^{c}$ & 0.17 \\
\hline
\end{tabular}

FAME, fatty acid methyl ester; ND, not detected.

${ }_{\mathrm{a}, \mathrm{b}, \mathrm{c}, \mathrm{d}, \mathrm{e}}$ Mean values within a row with unlike superscript letters were significantly different $(P<0 \cdot 05$; ANOVA followed by post hoc Tukey's multiple comparison test). 
Table 7. SCFA concentrations ( $\mu \mathrm{mol} / \mathrm{g}$ ) in the caecal contents of mice fed high-fat (HF) diets supplemented with either palm oil, olive oil, safflower oil or flaxseed/fish oil compared with those fed low-fat (LF) diets supplemented with either high sucrose or high maize starch for 16 weeks

(Mean values with their standard errors; $n 9-10$ mice per group)

\begin{tabular}{|c|c|c|c|c|c|c|c|c|c|c|c|c|}
\hline \multirow[b]{2}{*}{ SCFA } & \multicolumn{2}{|c|}{$\begin{array}{l}\text { LF-high maize } \\
\text { starch }\end{array}$} & \multicolumn{2}{|c|}{ LF-high sucrose } & \multicolumn{2}{|c|}{ HF-palm oil } & \multicolumn{2}{|c|}{ HF-olive oil } & \multicolumn{2}{|c|}{ HF-safflower oil } & \multicolumn{2}{|c|}{$\begin{array}{l}\text { HF-flaxseed/fish } \\
\text { oil }\end{array}$} \\
\hline & Mean & SEM & Mean & SEM & Mean & SEM & Mean & SEM & Mean & SEM & Mean & SEM \\
\hline Acetate & $31 \cdot 85^{a, b}$ & 1.55 & $24.53^{a}$ & 1.36 & $38.61^{b}$ & 4.03 & $25 \cdot 73^{\mathrm{a}}$ & 1.66 & $25 \cdot 91^{\mathrm{a}}$ & 1.19 & $27 \cdot 08^{a}$ & 1.04 \\
\hline Propionate & $14.84^{\mathrm{a}}$ & 0.93 & $11.02^{\mathrm{a}}$ & 0.46 & $19 \cdot 57^{b}$ & 2.03 & $11.87^{\mathrm{a}}$ & 1.19 & $11 \cdot 39^{a}$ & 0.83 & $11.90^{\mathrm{a}}$ & 0.62 \\
\hline Butyrate & $14.59^{a}$ & 1.06 & $11 \cdot 35^{a}$ & 0.56 & $21.56^{\mathrm{b}}$ & 2 & $11.42^{\mathrm{a}}$ & 1.24 & $11.45^{\mathrm{a}}$ & 1.25 & $12 \cdot 30^{\mathrm{a}}$ & 0.73 \\
\hline Isobutyrate & $10 \cdot 83^{a}$ & 1.03 & $8 \cdot 61^{a}$ & 0.62 & $16 \cdot 51^{\mathrm{b}}$ & 1.45 & $10 \cdot 25^{a}$ & 1.26 & $10 \cdot 21^{a}$ & 1.36 & $10 \cdot 21^{a}$ & 0.8 \\
\hline Total & $72 \cdot 10^{a, b}$ & 4.56 & $55 \cdot 51^{\mathrm{a}}$ & 3.01 & $96 \cdot 25^{\mathrm{b}}$ & 9.52 & $59 \cdot 27^{a}$ & 5.36 & $58.97^{a}$ & 4.62 & $61.50^{\mathrm{a}}$ & $3 \cdot 19$ \\
\hline
\end{tabular}

${ }^{a, b}$ Mean values within a row with unlike superscript letters were significantly different $(P<0.05$; ANOVA followed by post hoc Tukey's multiple comparison test).

were significantly different from each other. Principal coordinate analysis plots generated using an unweighted Unifrac distance matrix showed that mice clustered into relatively distinct groups based on dietary treatment (Fig. 3). This suggests that exposure to different qualities of dietary fats or different energy sources (fat $v$. carbohydrate) can significantly alter intestinal microbial populations.

Taxonomy-based analysis of the assigned sequences showed that at the phylum level, the mouse intestinal microbiota was dominated by Firmicutes and Bacteroidetes (together harbouring on average $92.3 \%$ of sequences; Fig. 4). At the family level, the most dominant groups were Lachnospiraceae, Erysipelotrichaceae, Ruminococcaceae, Rikenellaceae and Deferribacteraceae (Table 8 and Fig. 5). Consistent with the high levels of Firmicutes and Bacteroidetes detected, the dominant bacteria detected at the genus level were Allobaculum, Ruminococcaceae Incertae sedis, Bacteroides and Rikenella (Table 8 and Fig. 6).

The palm oil-fed group had reduced caecal populations of Bacteroidetes at the phylum level ( $P<0.05$; Fig. 4), at $10.5 \%$, compared with the olive oil- and safflower oil-fed groups (both 20\%). All the other phyla remained at relatively similar proportions across the groups. At the family level, the palm oil- and LF-high sucrose-fed groups had higher populations of Lachnospiraceae (46.4 and 49.6\%, respectively, $P<0.05$; Fig. 5) than the LF-high maize starch- and flaxseed/fish oil-fed groups (17.1 and $24 \cdot 2 \%$, respectively). Among the high-fat diets, as the degree of saturation shifted from the more SFA source of palm oil to the $n-3$ PUFA source of flaxseed/fish oil, the intestinal populations of Lachnospiraceae steadily decreased in a coinciding manner. Reduced proportions of Lachnospiraceae were also found in the safflower oil-fed group, relative to the LF-high sucrose-fed group $(P<0.05$; Fig. 5). Within the LF-high carbohydrate-fed groups, contrasting results were found. The relative proportions of Ruminococcaceae were higher in the high sucrose-fed group than in the high maize starch-fed group $(P<0.05$; Fig. 5), while the high maize starch-fed group had a higher population of Erysipelotrichaceae than the high sucrose-fed group $(P<0.05$; Fig. 5). The olive oil- and flaxseed/fish oil-fed groups had a greater abundance of Erysipelotrichaceae compared with the LF-high sucrose-fed group $(P<0 \cdot 05$; Fig. 5). Again, among the high-fat dietary groups, as the degree of saturation shifted from the more SFA source of palm oil to the $n-3$ PUFA source of flaxseed/fish oil, the intestinal populations of Erysipelotrichaceae steadily increased in a coinciding manner. Thus, the saturation or quality of fat can shift the intestinal microbiota population in numerous ways. Interestingly, higher proportions of Bacteroidaceae and Bacteroides were found in the olive oil-fed group compared with the palm oil-, flaxseed/fish oil- and LF-high sucrose-fed groups $(P<0.05$; Figs. 5 and 6). Additionally, the $n$-3 PUFA-rich flaxseed/fish oil diet was the only diet to increase intestinal populations of Bifidobacteriaceae and Bifidobacterium compared with the LF-high maize starch diet $(P<0.05$; Figs. 5 and 6$)$.

At the genus level, Allobaculum was found to be higher in the LF-high maize starch-, HF-flaxseed/fish oil- and HF-olive oil-fed groups than in the LF-high sucrose-fed group (38.9, $38.7,23.8$ and $5.4 \%$ respectively, $P<0.05$; Fig. 6). High populations of uncultured Lachnospiraceae, Oscillibacter, Odoribacter and Anaerotruncus were detected in the LF-high sucrose-fed group, reaching significance compared with a variety of different groups within each population $(P<0.05$; Table 8 and Fig. 6).

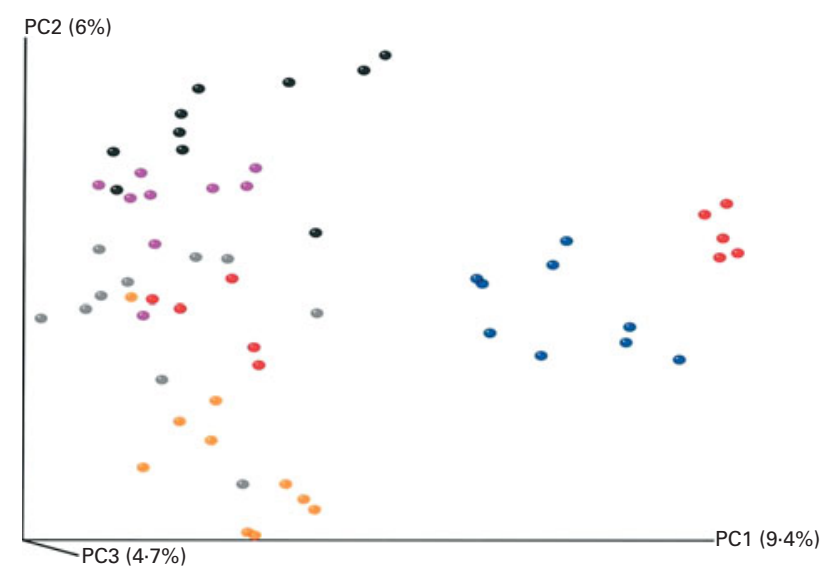

Fig. 3. Principal coordinate analysis using unweighted UniFrac distances for mice fed high-fat (HF) diets supplemented with either palm oil, olive oil, safflower oil or flaxseed/fish oil compared with those fed low-fat (LF) diets supplemented with either high sucrose or high maize starch for 16 weeks. LF-high maize starch group; «, HF-palm oil group; a HF-olive oil group; HF-safflower oil group; e, HF-flaxseed/fish oil group; e, LF-high sucrose group. 


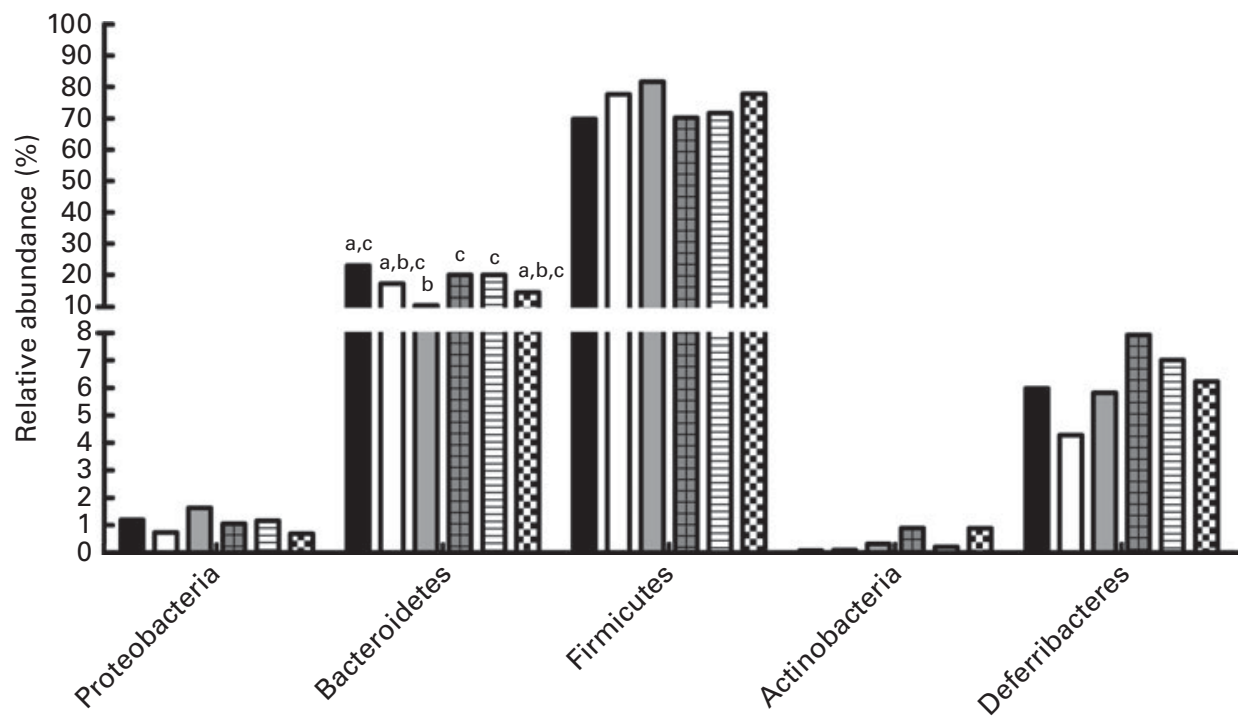

Fig. 4. Phylum-level distributions of the microbial communities in caecal contents, expressed as a percentage of the total population of assignable tags, in mice fed high-fat (HF) diets supplemented with either palm oil, olive oil, safflower oil or flaxseed/fish oil compared with those fed low-fat (LF) diets supplemented with either high sucrose or high maize starch for 16 weeks. ${ }^{a, b, c}$ Values with unlike letters were significantly different $(P<0.05$; Kruskal-Wallis algorithm). $\square$, LF-high maize starch; $\square$, LF-high sucrose; $\square$, HF-palm oil; $\boxplus$, HF-olive oil; $\boxminus$, HF-safflower oil; $/$, HF-flaxseed/fish oil.

\section{Discussion}

The data presented herein reveal that different dietary fatty acids and qualities of dietary fats from different sources (palm oil, olive oil, safflower oil and flaxseed/fish oil) and high-carbohydrate diets (maize starch and sucrose) significantly influenced both metabolic parameters and the composition of the intestinal microbiota in mice. The present study has further highlighted that consumption of MUFA and PUFA is generally healthful in comparison with SFA, whereby chronic dietary SFA intake (palm oil) for 16 weeks resulted in significant increases in the percentage of body-weight gain, the percentage of body fat mass, subcutaneous fat mass and plasma glucose and leptin concentrations compared with the other groups. In contrast, consumption of MUFA (olive oil) for 16 weeks was associated with a significant decrease in the percentage of body-weight gain and the percentage of body fat mass compared with mice ingesting a palm oil-rich diet. Current nutritional recommendations suggest that a reduction in SFA consumption with an increase in plant oils containing MUFA is desirable; however, the

Table 8. Intestinal microbiota composition (\% reads) in the caecal contents of mice fed high-fat (HF) diets supplemented with either palm oil, olive oil, safflower oil or flaxseed/fish oils compared with those fed low-fat (LF) diets supplemented with either high sucrose or high maize starch for 16 weeks ( 9-10 mice per group)

\begin{tabular}{|c|c|c|c|c|c|c|}
\hline & LF-high maize starch & LF-high sucrose & HF-palm oil & HF-olive oil & HF-safflower oil & HF-flaxseed/fish oil \\
\hline \multicolumn{7}{|l|}{ Phylum } \\
\hline Spirochaetes & 0.01 & 0.00 & 0.04 & 0.00 & 0.00 & 0.04 \\
\hline Candidate division TM7 & 0.00 & 0.00 & 0.04 & 0.01 & 0.00 & 0.00 \\
\hline \multicolumn{7}{|l|}{ Family } \\
\hline Desulfovibrionaceae & 0.91 & 0.68 & 0.96 & 1.00 & 0.85 & 0.52 \\
\hline Rikenellaceae & $9 \cdot 18$ & $6 \cdot 20$ & $3 \cdot 37$ & $6 \cdot 02$ & $6 \cdot 88$ & $5 \cdot 88$ \\
\hline Lactobacillaceae & $2 \cdot 41$ & 1.95 & $2 \cdot 24$ & 1.45 & $2 \cdot 25$ & 0.95 \\
\hline Deferribacteraceae & 5.98 & $4 \cdot 28$ & $5 \cdot 83$ & $7 \cdot 93$ & $7 \cdot 01$ & $6 \cdot 23$ \\
\hline Others & 0.94 & 0.93 & $2 \cdot 27$ & 0.55 & 0.87 & 0.72 \\
\hline \multicolumn{7}{|l|}{ Genus } \\
\hline Alistipes & $5 \cdot 50^{\mathrm{a}}$ & $3 \cdot 62^{a, b}$ & $1.83^{b}$ & $3 \cdot 05^{a, b}$ & $3 \cdot 87^{a, b}$ & $4 \cdot 17^{\mathrm{a}, \mathrm{b}}$ \\
\hline Rikenella & $3 \cdot 35$ & $2 \cdot 22$ & $1 \cdot 24$ & $2 \cdot 37$ & 2.48 & 1.42 \\
\hline Odoribacter & $1.06^{\mathrm{a}, \mathrm{b}}$ & $1.99^{a}$ & $0 \cdot 60^{a, b}$ & $0.09^{b}$ & $0.83^{a, b}$ & $2 \cdot 33^{a}$ \\
\hline Lachnospiraceae Incertae sedis & $0.59^{a, b}$ & $1 \cdot 28^{a}$ & $1 \cdot 12^{\mathrm{a}, \mathrm{b}}$ & $0.71^{a, b}$ & $0.47^{\mathrm{b}}$ & $0.62^{a, b}$ \\
\hline Uncultured (Lachnospiraceae) & $0 \cdot 21^{a, b}$ & $0.72^{a}$ & $0 \cdot 34^{a, b}$ & $0.07^{\mathrm{b}}$ & $0 \cdot 16^{a, b}$ & $0.38^{a, b}$ \\
\hline Coprococcus & 0.24 & 0.37 & 0.61 & 0.16 & 0.17 & 0.24 \\
\hline Anaerotruncus & $0.34^{a}$ & $0.99^{b}$ & $0.66^{\mathrm{a}, \mathrm{b}}$ & $0.48^{\mathrm{a}, \mathrm{b}}$ & $0.55^{\mathrm{a}, \mathrm{b}}$ & $0.42^{\mathrm{a}}$ \\
\hline Peptococcus & $0 \cdot 16$ & 0.22 & 0.31 & 0.07 & 0.25 & 0.19 \\
\hline Lactobacillus & $2 \cdot 41$ & 1.95 & $2 \cdot 24$ & 1.45 & $2 \cdot 25$ & 0.95 \\
\hline Mucispirillum & 5.98 & $4 \cdot 28$ & 5.83 & $7 \cdot 93$ & $7 \cdot 01$ & $6 \cdot 23$ \\
\hline Others & 1.58 & 0.97 & $2 \cdot 14$ & $1 \cdot 28$ & $1 \cdot 20$ & 0.95 \\
\hline
\end{tabular}

${ }^{\mathrm{a}, \mathrm{b}}$ Mean values within a row with unlike superscript letters were significantly different $(P<0 \cdot 05 ;$ Kruskal-Wallis algorithm). 


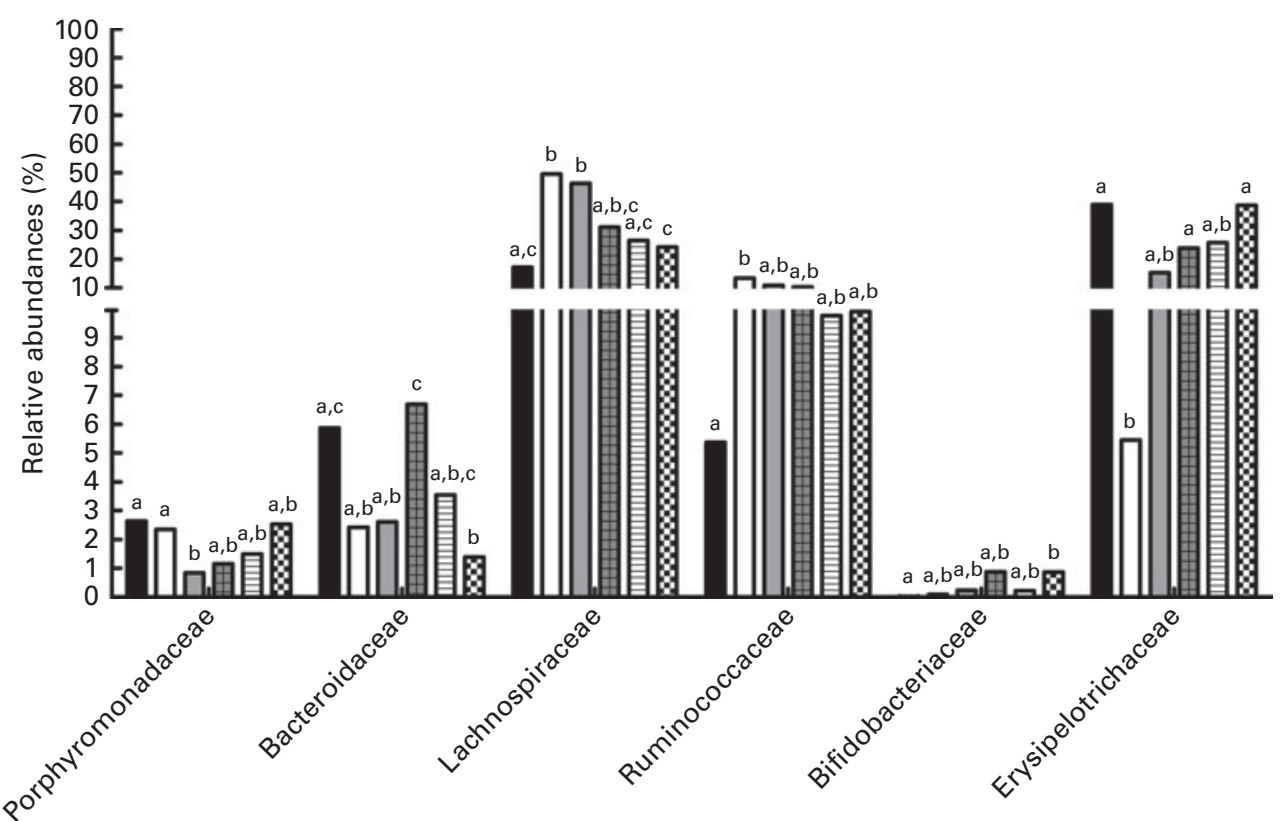

Fig. 5. Family-level taxonomic distributions of the microbial communities in caecal contents, expressed as a percentage of total tags assignable at the family level, in mice fed high-fat (HF) diets supplemented with either palm oil, olive oil, safflower oil or flaxseed/fish oil compared with those fed low-fat (LF) diets supplemented with either high sucrose or high maize starch for 16 weeks. ${ }^{a, b, c}$ Values with unlike letters were significantly different $(P<0.05$; Kruskal-Wallis algorithm). 匹, LF-high maize starch; $\square$, LF-high sucrose; $\square$, HF-palm oil; 田, HF-olive oil; 目, HF-safflower oil; 因, HF-flaxseed/fish oil.

mechanism by which MUFA may be responsible for a reduction in body weight is largely unknown. Recently, a study $^{(25)}$ has reviewed numerous health benefits associated with the polyphenol fraction of olive oil, such as anti-inflammatory and antioxidant activities, which may possibly provide further evidence for the positive impact the olive oil diet has on body-weight gain observed in the present study.

The group that ingested the LF-high sucrose diet had the lowest percentage of weight gain over the 16-week study period, while the LF-high maize starch-fed group exhibited a

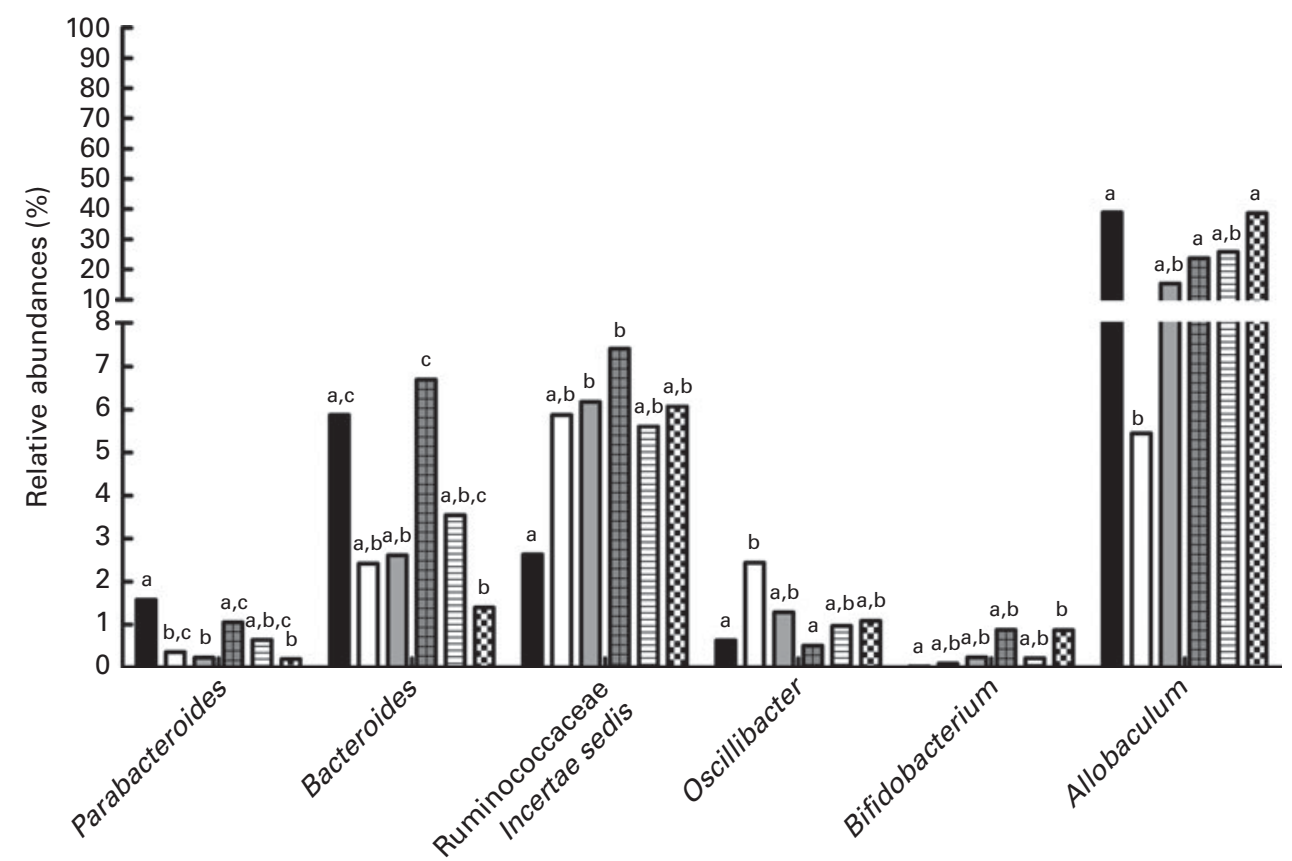

Fig. 6. Genus-level taxonomic distributions of the microbial communities present in caecal contents, expressed as a percentage of total tags assignable at the genus level, in mice fed high-fat (HF) diets supplemented with either palm oil, olive oil, safflower oil or flaxseed/fish oil compared with those fed low-fat (LF) diets supplemented with either high sucrose or high maize starch for 16 weeks. ${ }^{a, b, c}$ Values with unlike letters were significantly different $(P<0.05$; Kruskal-Wallis algorithm). . ., LF-high maize starch; $\square$, LF-high sucrose; $\square$, HF-palm oil; 田, HF-olive oil; 目, HF-safflower oil; 图, HF-flaxseed/fish oil. 
higher percentage of weight gain and plasma blood glucose levels compared with the high sucrose-fed group. This difference can partly be explained by the greater food intake of the high maize starch-fed group compared with the high sucrosefed group. The maize starch diet had a greater impact on food intake, glucose intolerance and weight gain, compared with dietary sucrose as the primary carbohydrate source in the diet. While a combination of high dietary fat with high sucrose has been reported to induce insulin resistance and glucose intolerance $^{(26)}$, it appears that dietary sucrose itself has differential effects depending on the amount of fat in the diet ${ }^{(27)}$.

Dietary SFA is known to play a substantial clinical role in the onset and progression of non-alcoholic fatty liver disease ${ }^{(28-30)}$. Supplementation with palm oil significantly increased both liver weight and TAG levels in mice after 16 weeks compared with all the other groups. Interestingly, it was shown herein that as the degree of saturation shifted from SFA (palm oil), to MUFA (olive oil), to $n$-6 PUFA (safflower oil) and finally to $n-3$ PUFA (flaxseed/fish oil), the levels of liver TAG steadily decreased in a coinciding manner. This indicates that it is not only the quantity of fat but also the quality of fat consumed that has an impact on the tissue distribution of fat in the host. Furthermore, the increased hepatic expression of Fas and Srebp-1c, which are involved in de novo lipogenesis, correlated with the increase in the levels of hepatic TAG observed for the palm oil-fed group.

The clinical implications of $n-3$ PUFA in preventing the progression of non-alcoholic fatty liver disease have been described $^{(31)}$. The reduced levels of liver TAG observed following dietary intake of flaxseed/fish oil for 16 weeks may be partly explained by the increase in the hepatic expression of PPAR $\gamma$ found for this group, given that PPAR $\gamma$ is associated with a reduction in inflammatory responses in the liver ${ }^{(32-34)}$. Furthermore, flaxseed/fish oil feeding increased the levels of $\alpha$-linolenic acid, EPA, docosapentaenoic acid and DHA in the liver, epididymal adipose tissue and brain. Dietary EPA and DHA exert anti-inflammatory properties ${ }^{(35)}$ by altering cytokine production $^{(36,37)}$, often at the expense of arachidonic acid, whereby pro-inflammatory eicosanoids derived from arachidonic acid, such as $\mathrm{PGE}_{2}$ and leukotriene $\mathrm{B}_{4}$, are replaced by anti-inflammatory eicosanoids derived from EPA and $\mathrm{DHA}^{(38)}$. The present study has demonstrated favourable increases in tissue EPA, docosapentaenoic acid and DHA and decreases in tissue arachidonic acid for the flaxseed/fish oil-fed group, whereby DHA has been shown to play important roles in neurogenesis, neurotransmission and protection against oxidative stress ${ }^{(39-41)}$. Importantly, the present study has demonstrated the ability of flaxseed/fish oil-derived fatty acids EPA, docosapentaenoic acid and DHA to cross the blood-brain barrier where it is understood that DHA may influence cognitive processes such as learning and memory in the brain ${ }^{(42,43)}$. This further highlights the importance of n-3 PUFA-derived dietary fatty acids to the brain-gut axis.

Diet composition significantly altered intestinal microbial populations and diversity after 16 weeks of feeding. A key finding was that all measures of $\alpha$ diversity demonstrated a high level of overall diversity between the dietary groups, whereby mice clustered into distinct groups based on dietary treatment. Decreases in the populations of Bacteroidetes and
Bacteroidaceae at the phylum and family levels, respectively, and increases in the population of Lachnospiraceae at the family level were observed for the palm oil-fed group. Interestingly, other studies have demonstrated similar trends in the Bacteroidetes population that positively correlate with the development of obesity ${ }^{(6,44)}$. Based on previous studies, it is generally understood that the gut microbiota can indeed increase the energy-harvesting capacity of the host through the fermentation of non-digestible complex polysaccharides in the intestine and thus producing SCFA ${ }^{(11,45)}$. In the present study, the palm oil-fed group increased total caecal SCFA produced compared with all the other groups. While the positive impact these SCFA have on human gastrointestinal health has previously been described ${ }^{(46-49)}$, the process by which they drive energy production has also been portrayed as a potential mechanism involved in the increase in host fat mass storage ${ }^{(11)}$. Furthermore, it is unclear whether the beneficial effect of SCFA is somehow compromised in obese subjects, or whether the effect is simply not strong enough to compensate for an adverse diet.

The group that ingested the olive oil-rich diet had increased populations of Bacteroidaceae in the caecum at the family level compared with the palm oil- and flaxseed/fish oil-fed groups. Interestingly, these bacteria maintain a complex and generally beneficial relationship with the host when retained in the gut and their role as commensals has been extensively reviewed $^{(50)}$. In the present study, between the two LF-high carbohydrate-fed groups, the proportions of Allobaculum were reduced while populations of Lachnospiraceae were increased in the caecum of the high sucrose-fed group compared with the maize starch-fed group. Interestingly, a recent study by Ravussin et al. ${ }^{(51)}$ reported an association between low-fat feeding and increases in the genus Allobaculum, thus suggesting that high dietary sucrose may be responsible for a reduction in the caecal numbers of Allobaculum.

The flaxseed/fish oil diet was the only diet to significantly increase the intestinal populations of Bifidobacteriaceae and Bifidobacterium, at the family and genus levels, respectively, possibly through the increased ability of flaxseed/fish oil to increase the adhesion of bifidobacteria to the intestinal wall.

The results from the present study indicate that dietary ingestion of different fatty acids in a high-fat diet, or a chronic intake of high levels of maize starch or sucrose significantly influences the distribution of fat in the host and also the composition of the intestinal microbiota. While subtle differences in the intestinal microbiota did exist between the two LF-high carbohydrate-fed groups in the present study, it is apparent that dietary maize starch has a greater impact on weight gain and glucose intolerance than sucrose. We demonstrated that dietary SFA (palm oil) had a negative impact on host metabolic parameters often associated with obesity and the metabolic syndrome, while also shifting the intestinal microbiota population to one similar to that seen in an obese phenotype. In contrast, dietary MUFA (olive oil) may beneficially alter the bacterial population in the intestine by increasing the populations of commensal bacteria. Finally, the present study has demonstrated that a rich dietary source of $n-3$ PUFA (flaxseed/fish oil) may have a bifidogenic effect on the 
intestinal microbiota composition of the host by increasing the levels of Bifidobacterium, while also positively influencing the composition of host tissues with $n-3$ PUFA-derived health-promoting fatty acids.

Indeed, the mechanism by which dietary fat types alter the intestinal microbiota remains largely to be elucidated. Promisingly, recent reports by Devkota et al. and de Wit et al. suggest that certain saturated fat types can alter conditions for gut microbial assemblage by promoting changes in host bile composition $^{(17)}$ and that an overflow of palm oil to the distal small intestine rather than obesity itself may trigger an elevation of lipid metabolism-related genes in the distal small intestine, thus altering the intestinal microbiota $^{(15)}$. Further future studies will confirm a precise mechanism by which diet alters the intestinal microbiota. In conclusion, the present study has demonstrated some novel findings on how different qualities of fat and energy subtypes have an impact on the metabolic health and intestinal microbiota composition of the host.

\section{Supplementary material}

To view supplementary material for this article, please visit http://dx.doi.org/10.1017/S0007114514000117

\section{Acknowledgements}

The authors acknowledge Aileen Hogan, Tatiana Marques and Eva Rosberg-Cody for technical assistance.

E. P. was supported by funding from the Teagasc Walsh Fellowship Scheme, and the present study was supported by the Science Foundation of Ireland-funded Centre for Science, Engineering and Technology, the Alimentary Pharmabiotic Centre, CSET grant 07/CE/B1368.

The authors' contributions were as follows: C. S., R. M. O. D., E. F. M., G. F. F. and R. P. R. designed the research; E. P., E. F. M., R. W., K. N. and P. D. C. conducted the research; E. P., E. F. M. and O. O' S. analysed the data; E. P. and C. S. wrote the manuscript; C. S. had primary responsibility for the final content.

The authors declare that there are no conflicts of interest.

\section{References}

1. Conterno L, Fava F, Viola R, et al. (2011) Obesity and the gut microbiota: does up-regulating colonic fermentation protect against obesity and metabolic disease? Genes Nutr $\mathbf{6}$, $241-260$.

2. Turnbaugh PJ, Backhed F, Fulton L, et al. (2008) Dietinduced obesity is linked to marked but reversible alterations in the mouse distal gut microbiome. Cell Host Microbe 3, $213-223$

3. Hildebrandt MA, Hoffmann C, Sherrill-Mix SA, et al. (2009) High-fat diet determines the composition of the murine gut microbiome independently of obesity. Gastroenterology 137, 1716-1724, e1711-e1712.

4. Turnbaugh PJ, Ridaura VK, Faith JJ, et al. (2009) The effect of diet on the human gut microbiome: a metagenomic analysis in humanized gnotobiotic mice. Sci Transl Med 1, Gra14.
5. Walker AW, Ince J, Duncan SH, et al. (2011) Dominant and diet-responsive groups of bacteria within the human colonic microbiota. Isme J 5, 220-230.

6. Ley RE, Turnbaugh PJ, Klein S, et al. (2006) Microbial ecology: human gut microbes associated with obesity. Nature 444, 1022-1023.

7. Qin J, Li R, Raes J, et al. (2010) A human gut microbial gene catalogue established by metagenomic sequencing. Nature 464, 59-65.

8. Backhed F, Ding H, Wang T, et al. (2004) The gut microbiota as an environmental factor that regulates fat storage. Proc Natl Acad Sci U S A 101, 15718-15723.

9. Guinane CM \& Cotter PD (2013) Role of the gut microbiota in health and chronic gastrointestinal disease: understanding a hidden metabolic organ. Therap Adv Gastroenterol 6, 295-308.

10. Murphy EF, Cotter PD, Healy S, et al. (2010) Composition and energy harvesting capacity of the gut microbiota: relationship to diet, obesity and time in mouse models. Gut 59, 1635-1642.

11. Turnbaugh PJ, Ley RE, Mahowald MA, et al. (2006) An obesity-associated gut microbiome with increased capacity for energy harvest. Nature 444, 1027-1031.

12. Schwiertz A, Taras D, Schafer K, et al. (2010) Microbiota and SCFA in lean and overweight healthy subjects. Obesity $\mathbf{1 8}$, 190-195.

13. Buettner R, Parhofer KG, Woenckhaus M, et al. (2006) Defining high-fat-diet rat models: metabolic and molecular effects of different fat types. $J \mathrm{Mol}$ Endocrinol 36, 485-501.

14. Liao FH, Liou TH, Shieh MJ, et al. (2010) Effects of different ratios of monounsaturated and polyunsaturated fatty acids to saturated fatty acids on regulating body fat deposition in hamsters. Nutrition 26, 811-817.

15. de Wit NJ, Derrien M, Bosch-Vermeulen H, et al. (2012) Saturated fat stimulates obesity and hepatic steatosis and affects gut microbiota composition by an enhanced overflow of dietary fat to the distal intestine. Am J Physiol Gastrointest Liver Physiol 303, G589-G599.

16. Mujico JR, Baccan GC, Gheorghe A, et al. (2013) Changes in gut microbiota due to supplemented fatty acids in dietinduced obese mice. Br J Nutr 110, 711-720

17. Devkota S, Wang Y, Musch MW, et al. (2012) Dietary-fatinduced taurocholic acid promotes pathobiont expansion and colitis in $\mathrm{Il10}^{-/-}$mice. Nature 487, 104-108.

18. Huang EY, Leone VA, Devkota S, et al. (2013) Composition of dietary fat source shapes gut microbiota architecture and alters host inflammatory mediators in mouse adipose tissue. JPEN J Parenter Enteral Nutr 37, 746-754.

19. Folch J, Lees M \& Sloane-Stanley GH (1957) A simple method for the isolation and purification of total lipides from animal tissues. J Biol Chem 226, 497-509.

20. Park PW \& Goins RE (1994) In-situ preparation of fatty-acid methyl-esters for analysis of fatty-acid composition in foods. J Food Sci 59, 1262-1266.

21. Caporaso JG, Kuczynski J, Stombaugh J, et al. (2010) QIIME allows analysis of high-throughput community sequencing data. Nat Methods 7, 335-336.

22. Altschul SF, Madden TL, Schaffer AA, et al. (1997) Gapped BLAST and PSI-BLAST: a new generation of protein database search programs. Nucleic Acids Res 25, 3389-3402.

23. Urich T, Lanzen A, Qi J, et al. (2008) Simultaneous assessment of soil microbial community structure and function through analysis of the meta-transcriptome. PLOS ONE $\mathbf{3}$, e2527.

24. Huson DH, Auch AF, Qi J, et al. (2007) MEGAN analysis of metagenomic data. Genome Res 17, 377-386. 
25. Martin-Pelaez S, Covas MI, Fito M, et al. (2013) Health effects of olive oil polyphenols: recent advances and possibilities for the use of health claims. Mol Nutr Food Res 57, 760-771.

26. Yang ZH, Miyahara H, Takeo J, et al. (2012) Diet high in fat and sucrose induces rapid onset of obesity-related metabolic syndrome partly through rapid response of genes involved in lipogenesis, insulin signalling and inflammation in mice. Diabetol Metab Syndr 4, 32

27. Surwit RS, Feinglos MN, Rodin J, et al. (1995) Differential effects of fat and sucrose on the development of obesity and diabetes in $\mathrm{C} 57 \mathrm{BL} / 6 \mathrm{~J}$ and $\mathrm{A} / \mathrm{J}$ mice. Metabolism 44, 645-651.

28. Wang D, Wei Y \& Pagliassotti MJ (2006) Saturated fatty acids promote endoplasmic reticulum stress and liver injury in rats with hepatic steatosis. Endocrinology 147, 943-951.

29. van den Berg SA, Guigas B, Bijland S, et al. (2010) High levels of dietary stearate promote adiposity and deteriorate hepatic insulin sensitivity. Nutr Metab (Lond) 7, 24.

30. Tetri LH, Basaranoglu M, Brunt EM, et al. (2008) Severe NAFLD with hepatic necroinflammatory changes in mice fed trans fats and a high-fructose corn syrup equivalent. Am J Physiol Gastrointest Liver Physiol 295, G987-G995.

31. Parker HM, Johnson NA, Burdon CA, et al. (2012) Omega-3 supplementation and non-alcoholic fatty liver disease: a systematic review and meta-analysis. $J$ Hepatol 56, 944-951.

32. Galli A, Crabb DW, Ceni E, et al. (2002) Antidiabetic thiazolidinediones inhibit collagen synthesis and hepatic stellate cell activation in vivo and in vitro. Gastroenterology 122, 1924-1940

33. Marra F, DeFranco R, Robino G, et al. (2005) Thiazolidinedione treatment inhibits bile duct proliferation and fibrosis in a rat model of chronic cholestasis. World J Gastroenterol 11, 4931-4938.

34. Marra F, Efsen E, Romanelli RG, et al. (2000) Ligands of peroxisome proliferator-activated receptor gamma modulate profibrogenic and proinflammatory actions in hepatic stellate cells. Gastroenterology 119, 466-478.

35. Mori TA \& Beilin LJ (2004) Omega-3 fatty acids and inflammation. Curr Atheroscler Rep 6, 461-467.

36. Calder PC (2001) Omega-3 polyunsaturated fatty acids, inflammation and immunity. World Rev Nutr Diet 88, 109-116.

37. Browning LM (2003) n-3 Polyunsaturated fatty acids, inflammation and obesity-related disease. Proc Nutr Soc 62, $447-453$.
38. Calder PC (2009) Polyunsaturated fatty acids and inflammatory processes: new twists in an old tale. Biochimie $\mathbf{9 1}$, 791-795.

39. Hashimoto M, Hossain S, Shimada T, et al. (2002) Docosahexaenoic acid provides protection from impairment of learning ability in Alzheimer's disease model rats. J Neurochem 81, 1084-1091.

40. Innis SM (2007) Dietary ( $n$-3) fatty acids and brain development. J Nutr 137, 855-859.

41. Lim GP, Calon F, Morihara T, et al. (2005) A diet enriched with the omega-3 fatty acid docosahexaenoic acid reduces amyloid burden in an aged Alzheimer mouse model. J Neurosci 25, 3032-3040.

42. Henriksen C, Haugholt K, Lindgren M, et al. (2008) Improved cognitive development among preterm infants attributable to early supplementation of human milk with docosahexaenoic acid and arachidonic acid. Pediatrics 121, 1137-1145.

43. Yurko-Mauro K, McCarthy D, Rom D, et al. (2010) Beneficial effects of docosahexaenoic acid on cognition in age-related cognitive decline. Alzheimers Dement 6, 456-464.

44. Turnbaugh PJ, Hamady M, Yatsunenko T, et al. (2009) A core gut microbiome in obese and lean twins. Nature 457, 480-484.

45. Jumpertz R, Le DS, Turnbaugh PJ, et al. (2011) Energybalance studies reveal associations between gut microbes, caloric load, and nutrient absorption in humans. Am J Clin Nutr 94, 58-65.

46. D'Argenio G, Cosenza V, Delle Cave M, et al. (1996) Butyrate enemas in experimental colitis and protection against large bowel cancer in a rat model. Gastroenterology 110, $1727-1734$.

47. Emenaker NJ, Calaf GM, Cox D, et al. (2001) Short-chain fatty acids inhibit invasive human colon cancer by modulating uPA, TIMP-1, TIMP-2, mutant p53, Bcl-2, Bax, p21 and PCNA protein expression in an in vitro cell culture model. J Nutr 131, 3041S-3046S.

48. Galvez J, Rodriguez-Cabezas ME \& Zarzuelo A (2005) Effects of dietary fiber on inflammatory bowel disease. Mol Nutr Food Res 49, 601-608

49. Topping DL \& Clifton PM (2001) Short-chain fatty acids and human colonic function: roles of resistant starch and nonstarch polysaccharides. Physiol Rev 81, 1031-1064.

50. Xu J \& Gordon JI (2003) Honor thy symbionts. Proc Natl Acad Sci U S A 100, 10452-10459.

51. Ravussin Y, Koren O, Spor A, et al. (2012) Responses of gut microbiota to diet composition and weight loss in lean and obese mice. Obesity 20, 738-747. 